Hydrology and Earth System Sciences, 10, 31-48, 2006

www.copernicus.org/EGU/hess/hess/10/31/

SRef-ID: 1607-7938/hess/2006-10-31

European Geosciences Union

\title{
Transport at basin scales: 2. Applications
}

\author{
A. Rinaldo, G. Botter, E. Bertuzzo, A. Uccelli, T. Settin, and M. Marani \\ International Centre for Hydrology "Dino Tonini” and Dipartimento IMAGE, Università di Padova, via Loredan 20, 35131 \\ Padova, Italy
}

Received: 6 July 2005 - Published in Hydrology and Earth System Sciences Discussions: 23 August 2005

Revised: 22 November 2005 - Accepted: 1 December 2005 - Published: 8 February 2006

\begin{abstract}
In this paper, the second of a series, we apply the models discussed in Part 1 to a significant case study. The nature of the catchment under study, the transport phenomena investigated (i.e. nitrates moving as solutes within runoff waters) and the scales involved in space and time, provide an elaborate test for theory and applications. Comparison of modeling predictions with field data (i.e. fluxes of carrier flow and solute nitrates) suggests that the framework proposed for geomorphic transport models is capable to describe well large-scale transport phenomena driven and/or controlled by spatially distributed hydrologic fields (e.g. rainfall patterns in space and time, drainage pathways, soil coverage and type, matter stored in immobile phases). A sample MonteCarlo mode of application of the model is also discussed where hydrologic forcings and external nitrate applications (through fertilization) are treated as random processes.
\end{abstract}

\section{Introduction}

Case studies of catchment models, in particular for brackish or lagoonal receiving water bodies, demand the prediction of event-based time distributions of pollution loads within hydrologic runoff waters. This is the case, in particular, for the Lagoon of Venice where a pointed debate rages over the environmental sustainability of repeated closures of the lagoon inlets needed in the long run to protect the city against catastrophic flooding under increasing relative sea level. To a fragile receiving water body, in fact, the pollution accumulated due to loads carried by hydrological waters (e.g. high levels of nutrients, pesticides, metals and/or other dissolved materials in the surface and subsurface waters that affect bioavailability) may cause a variety of problems, as one obviously expects. The observation that the main part of annual loads

Correspondence to: A. Rinaldo

(andrea.rinaldo@unipd.it) from nonpoint sources is carried by a few flood events rather than during normal hydrologic conditions is particularly relevant to our modelling approach but was somewhat little acknowledged up to now. Thus to devise a sustainable conservation of valuable water bodies one needs to predict the hydrologic response of catchments both in terms of quantity and quality of waters. Most pollutants potentially threatening the health of aquatic environments derive from land-use. They enter the hydrological cycle driven by mass exchange processes between the circulating water carrier and immobile phases where polluting substances are stored, temporarily or permanently (e.g. Rinaldo and Marani, 1987; Rinaldo et al., 1989a, 2005, 2006; Cvetkovic and Dagan, 1994; Gupta and Cvetkovic, 2002; Botter et al., 2005). Transported matter, once dissolved in the runoff, is then driven along the drainage network where it may possibly be involved with other chemical or physical reactions such as decay, sorption, ion exchange with the bed sediments or hyporheic zones.

The theoretical framework described in Part 1 of this paper is suited to investigate many practical issues related to nonpoint pollution phenomena and to basin scale transport and flow. For instance, transport processes occurring within the hillslopes, central in defining the features of the catchment travel time distributions even at surprisingly large scales (Wood et al., 1988; Botter et al., 2005), are also often chiefly responsible of the mobilization and release of solutes at catchment scale (e.g. Rinaldo et al., 1989b; Botter et al., 2005). The relatively small velocities driving the water particles within the hillslopes, in fact, are responsible for determining relatively large contact times between the soil and the hydrologic runoff, with pronounced implications for the resulting carrier concentration. Thus, the validity of the hypothesis of well-mixed transport conditions (briefly, MRF from mass-response functions) is crucial to our theoretical construction, and has been recently investigated (Botter et al., 2005) by comparison with less restrictive Lagrangian schemes (Cvetkovic and Dagan, 1994).

(C) 2006 Author(s). This work is licensed under a Creative Commons License. 
(a)

(b)

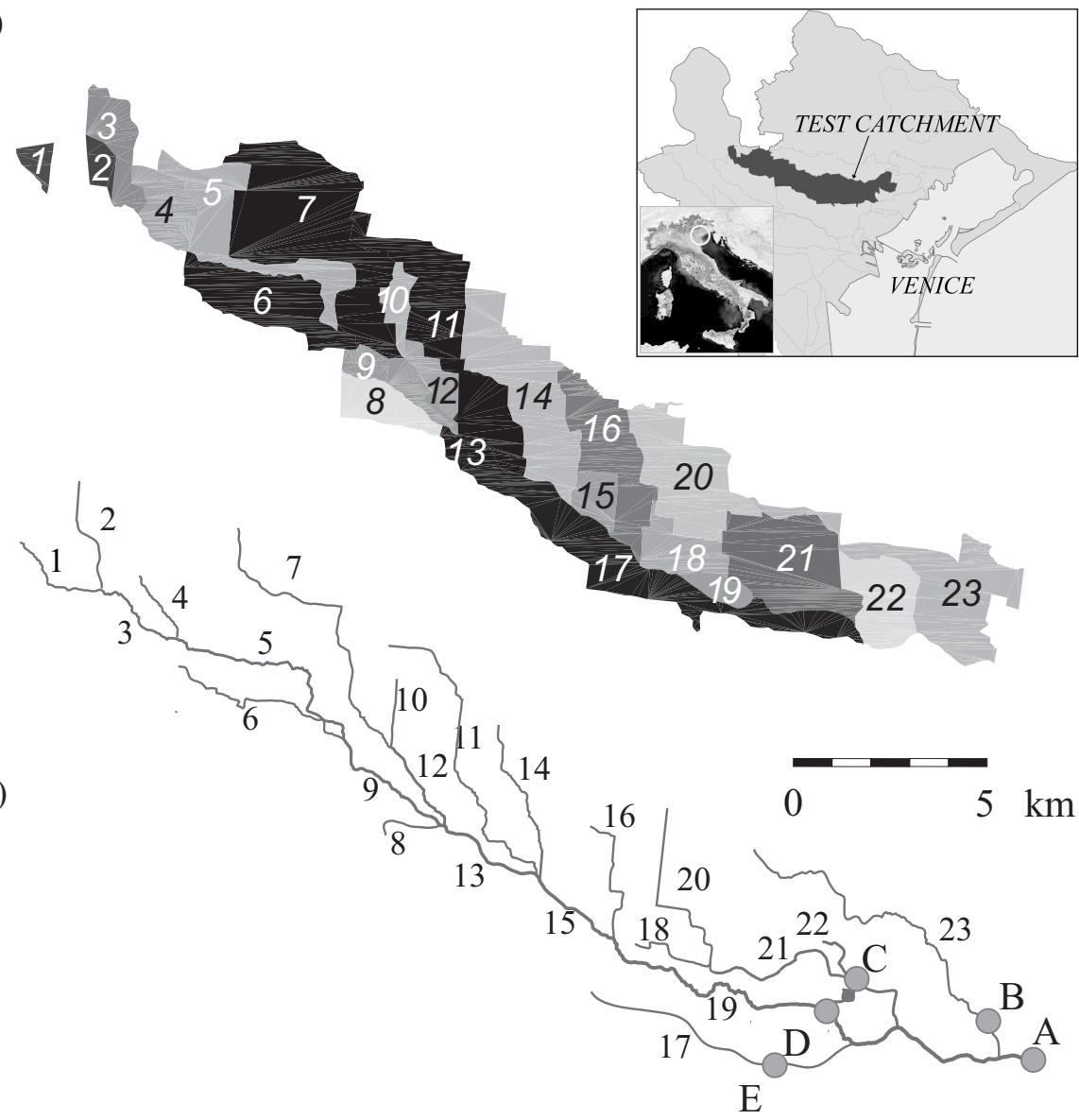

(c)

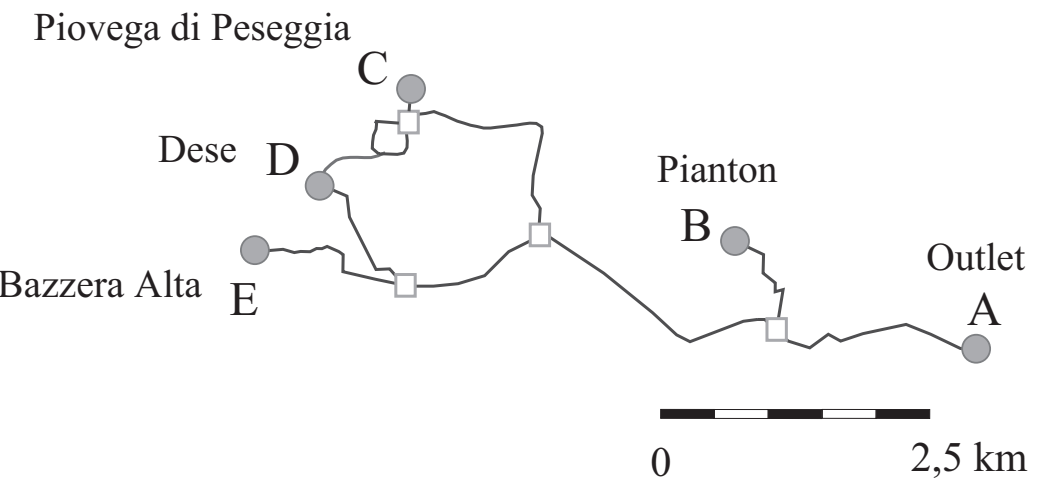

Fig. 1. The complete geomorphologic scheme of the catchment of the River Dese (Northern Italy) used in the modelling approach. Inset: geographical setting showing the receiving water body, the lagoon of Venice; (a) a labeled scheme of the 23 source areas in which the surface has been partitioned. Source areas are described in Table 1 jointly with their transitions to their outlet necessary to define the sequence of nested convolutions in Eq. (1); (b) the scheme of the hydraulic network, showing the runoff production zone (upstream of nodes B, C, D and E). Here A is the gauging station; (c) a detail of the tidal network, where independent hydrologic fluxes are treated as boundary conditions (nodes B, C, D, and E) for a routing model where downstream, oscillating elevations at node A need to be specified. The network embedded among nodes $\mathrm{A}$ to $\mathrm{E}$ is treated by numerically solving the proper momentum and continuity equations. 
In this paper, the geomorphic transport approach described in Part 1 is employed to describe the hydrologic response and the nitrate fluxes in a hydraulically complex catchment located in Northern Italy (see Fig. 1a): the Dese river basin and its tidal outlet reach, whose geomorphic and hydrologic features are well measured and documented.

\section{The test catchment and the hydrologic data}

The Dese river catchment (see Fig. 1) is a (roughly) $90 \mathrm{~km}^{2}$ large, flat basin discharging into the Venice lagoon (NorthEastern Italy). It is an elongated basin whose mainstream is about $35 \mathrm{~km}$ long, geomorphically characterized by groundwater-fed headwaters (where drainage density is low - e.g. source areas 1, 2, 3 and 23 in Fig. 1b) and mostly left tributaries owing to a gentle oblique slope of the Venetian plane. Such main tributaries, which drain both highly urbanized and/or extensive agricultural areas, are respectively from the mouth up, the rivers: Pianton, Piovega di Peseggia, Rio Desolino, Rio S. Martino, Rio S. Ambrogio (see Table 1).

In this case study, the partition between the solute and runoff generating areas and the transportation zone within the hydraulic network poses no problem as it is clearly determined by the nature of the site. In fact, four drops in bottom elevation at old mill sites (see e.g. Fig. $1 \mathrm{~b}-$ sites $E, D, C$, $B$ ) insure critical hydraulic depths at the closure of all four basins (namely, Bazzera Alta, Dese, Piovega di Peseggia and Pianton, see Fig. 1c) and, hence, a permanent transition to supercritical flow which grants the independence of the upstream reach from the downstream regimes. Therefore, the tidally affected reaches of the transportation zone (shown in Fig. 1c - here we do not show the tidal reach beyond the gauging site) and the hydrologic network are unambiguously determined regardless of the intensity of the tidal oscillations forced at the outlet. Runoff and solute fluxes are generated at the closure of the hydrologic reach via geomorphologic and mass-response function schemes. Such fluxes serve as input to routing numerical schemes of flow and transport within the tidal reach, which extends (Fig. 1c) for several kilometers up to the outlet into the Venice lagoon (where gauged water elevations are imposed as boundary conditions). Computed and measured quantities are compared at a gauging station (site $A$ in Fig. 1). They consist of suitable, synchronous time sequences of water discharges and nitrate flux concentrations. It should be noted that boundary conditions are much affected by the tidal regime of the northern fringes of the lagoon of Venice. This microtidal environment has an area of roughly $550 \mathrm{~km}^{2}$ and is characterized by a semidiurnal tidal regime with a range of about $\pm 0.7 \mathrm{~m}$ a.m.s.l. Results from recent field campaigns gathering hydrological and chemical data are available in Carrer et al. (1997); Bendoricchio et al. (1995, 1999); Zaggia et al. (2004); Collavini et al. (2005); Zuliani et al. (2005).
The model requires the subdivision of the catchment into suitable sub-basins. Following the procedure detailed in Part 1, we recall that, typically, the size of each source area needs be larger than the correlation scale of heterogeneous properties of transport and smaller than the maximum integral scales derived from equal-time covariances of rainfall intensity fields. In such case, one treats the kriged rainfall as spatially constant within a source area, and much simplified theoretical tools apply (i.e. Eqs. 25 and 26, Part 1). The choice of subbasins is shown in Fig. 1a - the average source area turned out to be roughly $4 \mathrm{~km}^{2}$. The resulting average characteristic size is $\mathrm{O}(1) \mathrm{km}$, smaller than the computed correlation length of intense rainfall which falls in the range 10$30 \mathrm{~km}$ (Rinaldo et al., 2003). The overall resolved drainage density is somewhat smaller than the actual one (Rinaldo et al., 2003). Note, however, that finer channelizations than resolved prove immaterial to the description of the basin-scale response, provided that their effect is embedded into suitable residence time distributions. Note also that in this case no digital elevation maps can be used to yield drainage directions along topographic steepest descent because of the flat nature of the overland areas. Since the geomorphologic path probabilities cannot be deduced from topography, different types of mapping information have been carefully analyzed to obtain the whole system description (shown in Figs. 1 and 2, see Table 1 for a summary; see Rinaldo et al., 2003, for technical details).

Available hydrologic data consisted of:

- hourly precipitation measurements available in 13 gauging stations within, and in the proximity of, the study basin (provided by Consorzio Venezia Nuova, see Rinaldo et al., 2003). The average distance between any two gauges is less than $10 \mathrm{~km}$, smaller than the correlation length of intense rainfall events in this zone;

- meteorological information about daily solar radiation, minimum and maximum air temperature, minimum and maximum air humidity and wind speed gauged at the standard height of $2 \mathrm{~m}$, available at the same stations. These data sets constitute a database suitable for accurate computations of point values of evapotranspiration (provided by Consorzio Venezia Nuova, see e.g. Rinaldo et al., 2003);

- continuous water elevations and discharge measurements at a control section at the outlet of the system (site A in Figs. 1b and 1c) for long timespans (provided by Consorzio Venezia Nuova, see e.g. Rinaldo et al., 2003);

- field measurements of nitrate concentrations (Carrer et al., 1997; Bendoricchio et al., 1995, 1999; Zaggia et al., 2004; Collavini et al., 2005; Zuliani et al., 2005) at the same control section at time intervals $(1 \mathrm{~h}$, in a few cases $1 / 2 \mathrm{~h}$ ) significantly smaller than the lead time of the hydrologic response $(\sim 8 \mathrm{~h})$ for a few events taken from 
Table 1. Geomorphic transitions for the transport model. The transitions refer to the legend of Fig. 1. Source areas are numbered in Fig. 1a. For every channel state, $c_{k}$, we have collected hydraulic, topographic and geomorphic information that allows the uncalibrated determination of the $k$-th reach length, $L_{k}$, the reach slope, bankfull width and depth (Rinaldo et al., 2003). From such information we derive information usable by the geomorphic scheme to derive the travel time distributions $f_{c_{k}}(t)$ and $f_{A_{k}}(t), k=1, \ldots, 23$, where the hydraulic parameters are the (bankfull) celerity of propagation, say $a_{k}$ and the average hydrodynamic dispersion coefficient $D_{k}$ for the channels (Table 2) and a single coefficient, $\mu$, relating the average residence time $\left\langle T_{k}\right\rangle$ to the area $A_{k}$ (Table 2). Details on the geometrical and hydraulic parameters are not reported for brevity and are available upon request (see e.g. Rinaldo et al., 2003).

\begin{tabular}{|c|c|c|}
\hline Source area & Geomorphic transitions & Legend \\
\hline $\begin{array}{l}\text { Dese - Origins } \\
\text { (1) }\end{array}$ & $\begin{array}{c}A_{1} \rightarrow c_{1} \rightarrow c_{3} \rightarrow c_{5} \rightarrow c_{9} \rightarrow \\
c_{13} \rightarrow c_{15} \rightarrow c_{19} \rightarrow D\end{array}$ & $\begin{array}{l}\text { Area }=0.64 \mathrm{~km}^{2} \\
\text { Fraction of cropland }=62 \%\end{array}$ \\
\hline $\begin{array}{l}\text { Musoncello } \\
\text { (2) }\end{array}$ & $\begin{array}{l}A_{2} \rightarrow c_{2} \rightarrow c_{3} \rightarrow c_{5} \rightarrow c_{9} \rightarrow \\
\quad \rightarrow c_{13} \rightarrow c_{15} \rightarrow c_{19} \rightarrow D\end{array}$ & $\begin{array}{l}\text { Area }=0.77 \mathrm{~km}^{2} \\
\text { Fraction of cropland }=71 \%\end{array}$ \\
\hline $\begin{array}{l}\text { Fossetta } \\
\text { (3) }\end{array}$ & $\begin{array}{c}A_{3} \rightarrow c_{3} \rightarrow c_{5} \rightarrow c_{9} \rightarrow c_{13} \rightarrow \\
\rightarrow c_{15} \rightarrow c_{19} \rightarrow D\end{array}$ & $\begin{array}{l}\text { Area }=2.41 \mathrm{~km}^{2} \\
\text { Fraction of cropland }=62 \%\end{array}$ \\
\hline $\begin{array}{l}\text { Rio Bianco } \\
\text { (4) }\end{array}$ & $\begin{array}{c}A_{4} \rightarrow c_{4} \rightarrow c_{5} \rightarrow c_{9} \rightarrow c_{13} \rightarrow \\
\rightarrow c_{15} \rightarrow c_{19} \rightarrow D\end{array}$ & $\begin{array}{l}\text { Area }=2.08 \mathrm{~km}^{2} \\
\text { Fraction of cropland }=59 \%\end{array}$ \\
\hline $\begin{array}{l}\text { Piovega di Levada } \\
\text { (5) }\end{array}$ & $\begin{aligned} A_{5} \rightarrow c_{5} & \rightarrow c_{9} \rightarrow c_{13} \rightarrow c_{15} \rightarrow \\
& \rightarrow c_{19} \rightarrow D\end{aligned}$ & $\begin{array}{l}\text { Area }=4.78 \mathrm{~km}^{2} \\
\text { Fraction of cropland }=59 \%\end{array}$ \\
\hline $\begin{array}{l}\text { Scolo Trego } \\
(6)\end{array}$ & $\begin{aligned} A_{6} \rightarrow c_{6} & \rightarrow c_{9} \rightarrow c_{13} \rightarrow c_{15} \rightarrow \\
& \rightarrow c_{19} \rightarrow D\end{aligned}$ & $\begin{array}{l}\text { Area }=4.36 \mathrm{~km}^{2} \\
\text { Fraction of cropland }=49 \%\end{array}$ \\
\hline $\begin{array}{l}\text { Rio S. Ambrogio } \\
\text { (7) }\end{array}$ & $\begin{aligned} A_{7} \rightarrow c_{7} & \rightarrow c_{12} \rightarrow c_{13} \rightarrow c_{15} \rightarrow \\
& \rightarrow c_{19} \rightarrow D\end{aligned}$ & $\begin{array}{l}\text { Area }=10.78 \mathrm{~km}^{2} \\
\text { Fraction of cropland }=62 \%\end{array}$ \\
\hline $\begin{array}{l}\text { Fossa del Pamio } \\
\text { (8) }\end{array}$ & $\begin{aligned} A_{8} \rightarrow & c_{8} \rightarrow c_{13} \rightarrow c_{15} \rightarrow \\
& \rightarrow c_{19} \rightarrow D\end{aligned}$ & $\begin{array}{l}\text { Area }=2.31 \mathrm{~km}^{2} \\
\text { Fraction of cropland }=51 \%\end{array}$ \\
\hline $\begin{array}{l}\text { Dese } \\
(9)\end{array}$ & $\begin{aligned} A_{9} \rightarrow & c_{9} \rightarrow c_{13} \rightarrow c_{15} \rightarrow \\
& \rightarrow c_{19} \rightarrow D\end{aligned}$ & $\begin{array}{l}\text { Area }=1.57 \mathrm{~km}^{2} \\
\text { Fraction of cropland }=47 \%\end{array}$ \\
\hline $\begin{array}{l}\text { Piovega Tre Comuni } \\
\text { (10) }\end{array}$ & $\begin{array}{c}A_{10} \rightarrow c_{10} \rightarrow c_{12} \rightarrow c_{13} \rightarrow c_{15} \rightarrow \\
c_{19} \rightarrow D\end{array}$ & $\begin{array}{l}\text { Area }=0.98 \mathrm{~km}^{2} \\
\text { Fraction of cropland }=47 \%\end{array}$ \\
\hline $\begin{array}{l}\text { Rio S. Martino } \\
\text { (11) }\end{array}$ & $A_{11} \rightarrow c_{11} \rightarrow c_{15} \rightarrow c_{19} \rightarrow D$ & $\begin{array}{l}\text { Area }=7.70 \mathrm{~km}^{2} \\
\text { Fraction of cropland }=45 \%\end{array}$ \\
\hline $\begin{array}{l}\text { Rio S. Ambrogio } \\
\text { (12) }\end{array}$ & $\begin{aligned} A_{12} \rightarrow & c_{12} \rightarrow c_{13} \rightarrow c_{15} \rightarrow \\
& \rightarrow c_{19} \rightarrow D\end{aligned}$ & $\begin{array}{l}\text { Area }=1.06 \mathrm{~km}^{2} \\
\text { Fraction of cropland }=45 \%\end{array}$ \\
\hline $\begin{array}{l}\text { Dese } \\
(13)\end{array}$ & $A_{13} \rightarrow c_{13} \rightarrow c_{15} \rightarrow c_{19} \rightarrow D$ & $\begin{array}{l}\text { Area }=0.73 \mathrm{~km}^{2} \\
\text { Fraction of cropland }=25 \%\end{array}$ \\
\hline $\begin{array}{l}\text { Scolo Desolino } \\
\text { (14) }\end{array}$ & $A_{14} \rightarrow c_{14} \rightarrow c_{15} \rightarrow c_{19} \rightarrow D$ & $\begin{array}{l}\text { Area }=7.43 \mathrm{~km}^{2} \\
\text { Fraction of cropland }=66 \%\end{array}$ \\
\hline $\begin{array}{l}\text { Desolino Vecchio } \\
\text { (15) }\end{array}$ & $A_{15} \rightarrow c_{15} \rightarrow c_{19} \rightarrow D$ & $\begin{array}{l}\text { Area }=1.27 \mathrm{~km}^{2} \\
\text { Fraction of cropland }=66 \%\end{array}$ \\
\hline $\begin{array}{l}\text { Piovega Cappella } \\
\text { (16) }\end{array}$ & $A_{16} \rightarrow c_{16} \rightarrow c_{19} \rightarrow D$ & $\begin{array}{l}\text { Area }=4.77 \mathrm{~km}^{2} \\
\text { Fraction of cropland }=66 \%\end{array}$ \\
\hline $\begin{array}{l}\text { Scolo Bazzera } \\
(17)\end{array}$ & $A_{17} \rightarrow c_{17} \rightarrow E$ & $\begin{array}{l}\text { Area }=7.98 \mathrm{~km}^{2} \\
\text { Fraction of cropland }=48 \%\end{array}$ \\
\hline $\begin{array}{l}\text { Fosso del Tarú } \\
\text { (18) }\end{array}$ & $A_{18} \rightarrow c_{18} \rightarrow c_{21} \rightarrow C$ & $\begin{array}{l}\text { Area }=1.80 \mathrm{~km}^{2} \\
\text { Fraction of cropland }=66 \%\end{array}$ \\
\hline $\begin{array}{l}\text { Dese Villa Volpi } \\
\text { (19) }\end{array}$ & $A_{19} \rightarrow c_{19} \rightarrow D$ & $\begin{array}{l}\text { Area }=0.90 \mathrm{~km}^{2} \\
\text { Fraction of cropland }=66 \%\end{array}$ \\
\hline $\begin{array}{l}\text { Scolo Peseggiana } \\
(20)\end{array}$ & $A_{20} \rightarrow c_{20} \rightarrow c_{21} \rightarrow C$ & $\begin{array}{l}\text { Area }=5.69 \mathrm{~km}^{2} \\
\text { Fraction of cropland }=61 \%\end{array}$ \\
\hline $\begin{array}{l}\text { Peseggia } \\
(21)\end{array}$ & $A_{21} \rightarrow c_{21} \rightarrow C$ & $\begin{array}{l}\text { Area }=9.91 \mathrm{~km}^{2} \\
\text { Fraction of cropland }=60 \%\end{array}$ \\
\hline $\begin{array}{l}\text { Peseggia Deviatore } \\
\text { (22) }\end{array}$ & $A_{22} \rightarrow c_{22} \rightarrow C$ & $\begin{array}{l}\text { Area }=3.40 \mathrm{~km}^{2} \\
\text { Fraction of cropland }=55 \%\end{array}$ \\
\hline $\begin{array}{l}\text { Scolo Pianton } \\
(23)\end{array}$ & $A_{23} \rightarrow c_{23} \rightarrow B$ & $\begin{array}{l}\text { Area }=6.80 \mathrm{~km}^{2} \\
\text { Fraction of cropland }=54 \%\end{array}$ \\
\hline
\end{tabular}




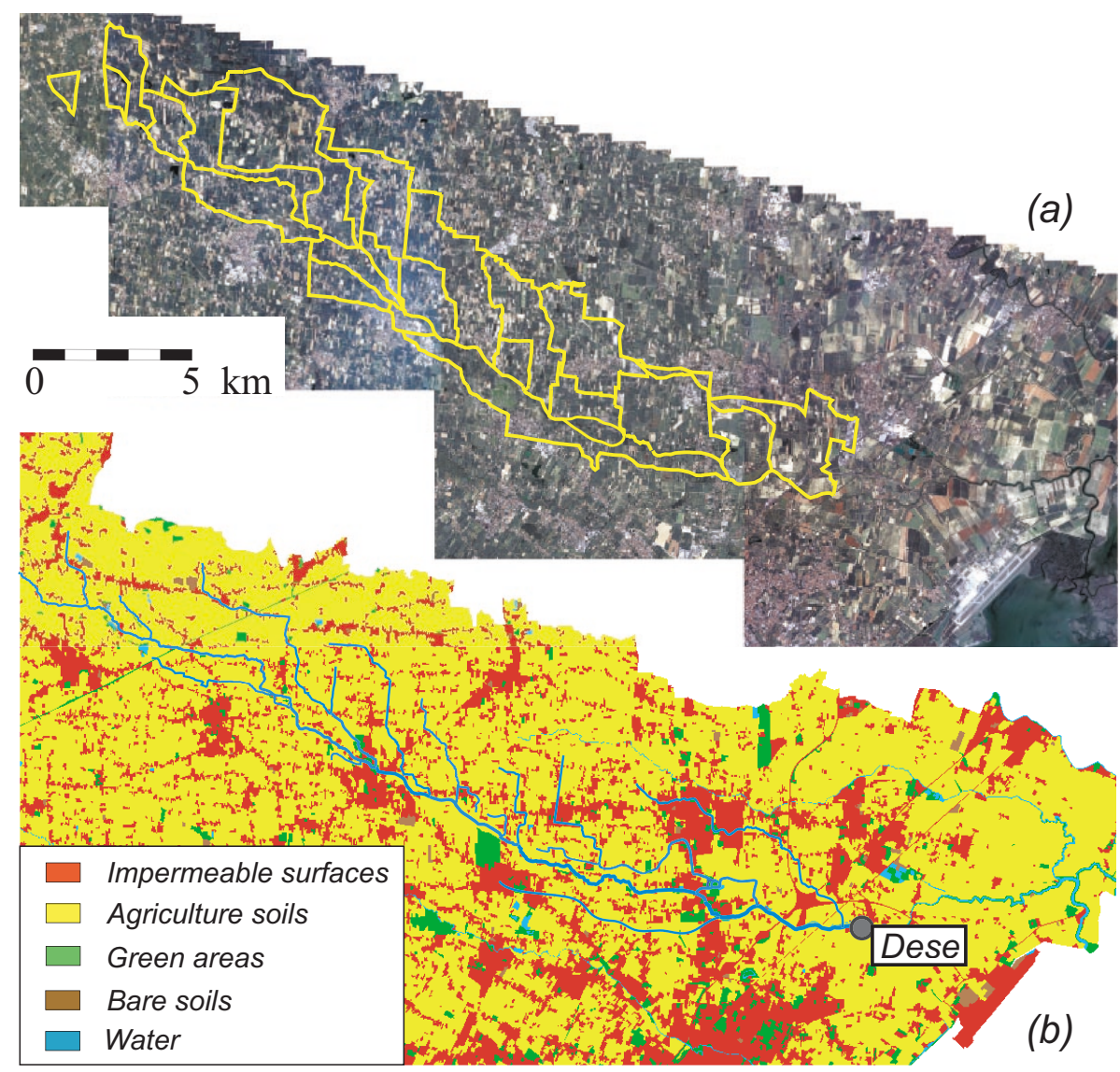

Fig. 2. (a) Remotely sensed image (IKONOS) of the Dese river basin (provided by Consorzio Venezia Nuova-Magistrato alle Acque di Venezia) and partition into subbasins; (b) Thematic map of land use of the catchment: classes of land use that are relevant to the modelling of water balance processes are indicated.

elaborate field campaigns reported in the above references;

- distributed information on the different land uses are derived from extensive databases of remotely sensed data. Image processing relies on extensive experience on the recognition of surface properties of hydrologic relevance in this context (Giandon et al., 2001; Marani et al., 2004).

Spatially distributed information on both the rainfall fields (Fig. 4) and on the soil properties (Figs. 2 and 3) provide a resonably complete description of the different regions of the basin. We employ geostatistical tools (e.g. Goovaerts, 1997) as shown in Fig. 4 for measured rainfall data. Kriged rainfall intensities are integrated over every source area at time steps of $1 \mathrm{~h}$ - see Sect. 4 and also Rinaldo et al. (2003) for details. This allows to achieve the temporal evolution of the spatial distribution of the rainfall volumes, which in turn defines time-dependent path probabilities for all the 23 subbasins of the system, as well as their input flowrate (Part 1 - Eq. 23). Details on the standard kriging procedure can be found elsewhere (Rinaldo et al., 2003).
The spatial distribution of soil types has been derived from published soil texture maps (Giandon et al., 2001). The catchment at hand is characterized by highly heterogeneous and temporally variable soil uses, typical of the developed mainland of the runoff-contributing areas to the lagoon of Venice (Figs. 2 and 3). Different urbanization levels are observed (see Fig. 2b) and they obviously need be carefully detected owing to the embedded, radically different processes of runoff and solute generation and transport. The use of remotely sensed data (IKONOS multispectral data, Fig. 2a) and ground truths (to identify the spectral signatures of relevant soil uses and crop types) has allowed a spatially-distributed and updated description of the soil uses which exerts a fundamental control on the soil mosture dynamics and the ensuing runoff production. The classification procedure adopted was based on the spectral angle mapper (SAM) algorithm (Kruse et al., 1993) and its application is shown in Fig. 3. The study area has been classified by subdividing it into seven classes (urban; cropland, namely: grain, maize, soybean, wood and grass; bare soil; water). We assumed null saturated soil conductivity (Sect. 3) for water and strictly urban zones, where 

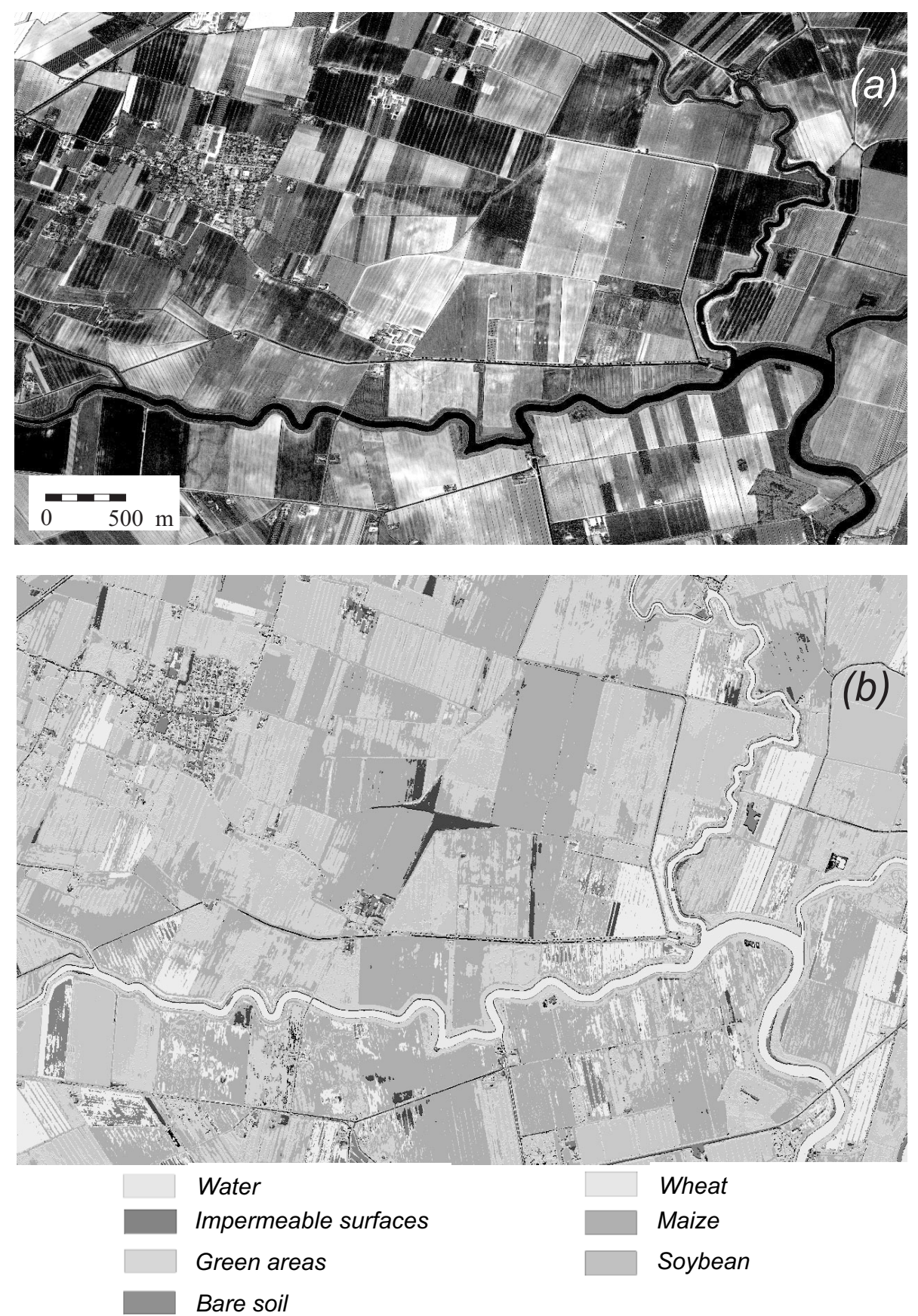

Fig. 3. Remote sensing tools: example of land-use classification of a small area in the test catchment between the outlet and the Venice Lagoon. The classification procedure is applied to the entire basin and employs characteristic ratios of relevant soil parameters coarse grained at the scale of source areas. Fraction of agricultural areas are used to estimate total nitrate mass in immobile phases. Technical details can be found in Rinaldo et al. (2003).

rainfall forcings contribute solely to overland flow. Otherwise, the value of the saturated conductivity in the other areas has been obtained under the constraint of fixed ratios between the saturated conductivity pertaining to different land use classes. Note that we rely on literature data for the establishment of the above ratios as a function of the various soil types and/or uses (Dingman, 1994). This has clear opera- tional advantages. In fact, the number of degrees of freedom is reduced from the overall number of soil texture and land use classes, to the one corresponding to the specific value of the saturated conductivity for the reference class, which thus becomes the sole calibration parameter (Rinaldo et al., 2003). 

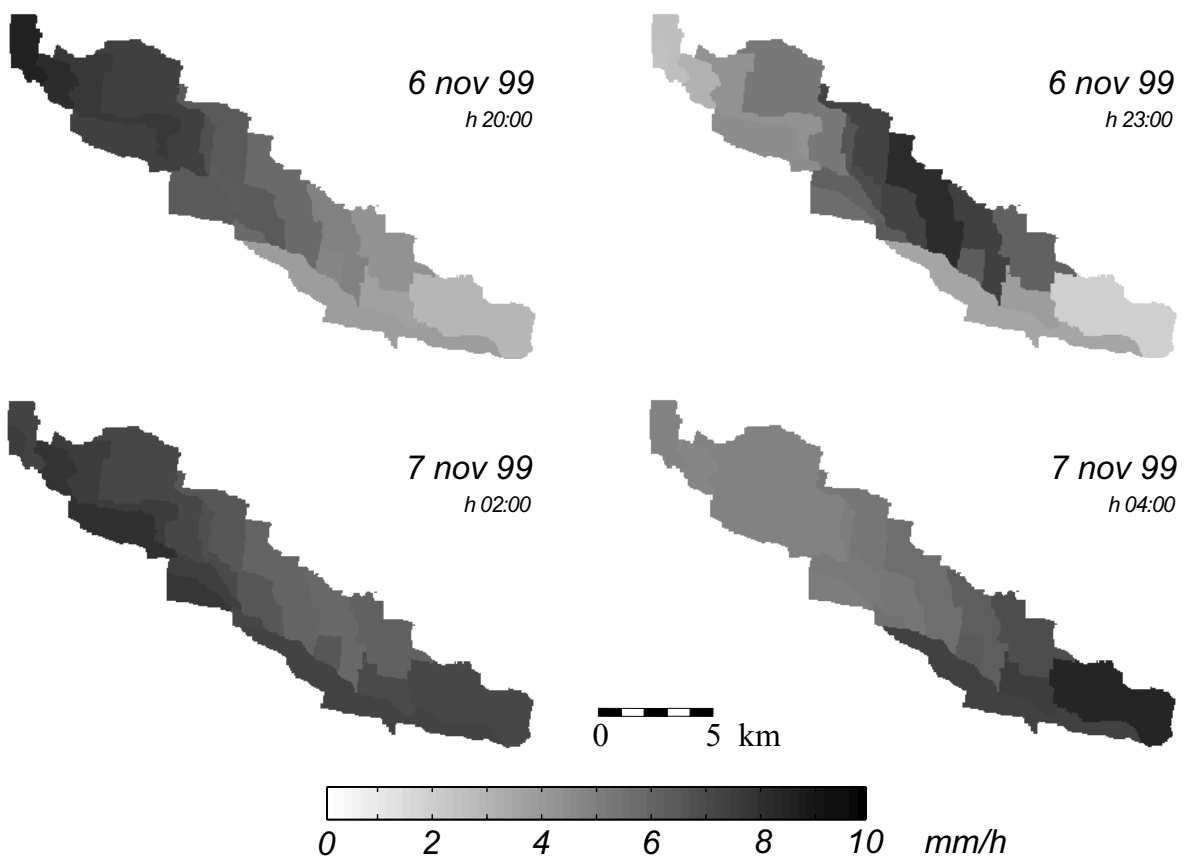

Fig. 4. Rainfall fields generated by kriging (of 13 point measurements) from rainfall gauges in the Dese area. We interpolate the rainfall point measurements at every time step $(1 \mathrm{~h})$ to produce the relative amount of rainfall entering each of the 23 source areas defined in Fig. 1 , which thus determines the ensuing path probabilities (changing in time owing to the variability of the rainfall patterns).

\section{Runoff production}

An obvious source of uncertainty in models of the hydrologic response is the estimate of runoff on the basis of climate, soil use and vegetative state. A continuously updated description of the instantaneous maximum infiltration rate within each source area $A_{\gamma}$, say $\varphi_{\gamma}(\mathrm{t})$, is achieved by the use of the Green-Ampt model for shallow soils (e.g. Dingman, 1994) (see caption of Table 2). When the water-input rate $J(\gamma, t)$ (see e.g. Part 1, Eq. 23) is less than the maximum infiltration rate $\varphi_{\gamma}(t)$ all the rainfall infiltrates into the soil (i.e. $J(\gamma, t)$ becomes the actual infiltration rate). For rainfall intensities $J(\gamma, t)$ greater than $\varphi_{\gamma}(t)$, instead, a rate $\varphi_{\gamma}(t)$ infiltrates while the difference between the input rate and the maximum infiltration rate $J(\gamma, t)-\varphi_{\gamma}(t)$ moves relatively quickly toward a stream channel (typical drainage densities relate to average unchanneled lengths that are at most a few hundred meters for this case study) and originates the short-term response of the basin. A prescribed fraction of the infiltrating volumes contributes to the recharge of the water table, while the residual fraction, say $\eta$, contributes to the groundwater flow toward the channel network.

A continuously updated mathematical model has been employed in order to evaluate the evapotranspiration rates contributing to runoff production. The evapotranspiration term cannot be neglected for timescales greater than the typical duration of single events, since it controls soil moisture at the beginning of each rainfall event. The model estimates the energy available to turn liquid water into vapour (which is calculated as the instantaneous atmospheric water deficit), as well as the surface turbulent transport mechanism and the vegetation transpiration constraints which concur to define the rate of vapour removal from the soil surface. Standard models of the relevant processes range from empirical to sophisticated (e.g. Brutsaert, 1984; Chen et al., 1996) and the choice of a suitable model must be made by balancing the overall accuracy required and the amount of information reasonably available at basin scales. We adopted the Penman-Monteith equation (e.g. Dingman, 1994) integrated by the FAO approach (e.g. Allen et al., 2005), which allows a theoretically sound evaluation of evapotranspiration through (relatively) few micro-meteorological, soil and vegetation parameters whose spatial distribution is determined via remotely sensed image analysis.

Evapotranspiration fluxes for an ideal reference vegetation under well-watered conditions and actual evapotranspiration rates of vegetation types or crops are determined as in Allen et al. (2005), p. 4, Eq. (3) through the parameters reported in caption of Table 2. Note that the formulation employed properly considers also the effect of reduced plant transpiration induced by insufficient soil water contents (Allen et al., 2005; Porporato et al., 2001; Williams and Albertson, 2004).

The evaluation of the seasonally changing crop characteristics, of the atmospheric forcing, of the resulting soil water content and evapotranspiration are performed on a daily time scale, allowing the explicit solution of the energy and water 
Table 2. Calibrated flow parameters. A legend discusses technicalities whose complete discussion, clearly outside the scopes of this paper, is in the related technical Reports (Rinaldo et al., 2003). Actual infiltration rates within each subbasin, $\varphi_{\gamma}$, are computed by the runoff production model via the equation (e.g. Dingman, 1994): $\varphi_{\gamma}(t)=K_{s}^{\gamma} A_{\gamma}\left[1+\psi_{f}^{\gamma}\left(\phi-\theta_{0}\right) / \Phi_{\gamma}(t)\right]$, where $\phi$ is the porosity, $\theta_{0}$ is the initial water content - immaterial in continuous simulations, $\Phi_{\gamma}(t)$ is the total amount of infiltration up to time $t, A_{\gamma}$ is the subbasin area, whereas $K_{s}^{\gamma}$ and $\psi_{f}^{\gamma}$ are, respectively, the average saturated hydraulic conductivity and the average tension head within the considered source area. $K_{S}^{\gamma}$ is computed by averaging the saturated conductivities of the different soil classes, $K_{S}^{c}$, weighted by their relative extension. Moreover, the value of $K_{S}^{c}$ for the different classes has been obtained on the basis of the calibrated saturated conductivity of the reference class $K_{S}^{R}$ as: $K_{S}^{c}=K_{s}^{R} \cdot \alpha^{c, R}$, where the ratios $\alpha^{c, R}$ have been kept fixed following Dingman (1994), Table 6.1. Average values of the tension head within each subbasin, $\psi_{f}^{\gamma}$, are computed in a similar manner on the basis of the uncalibrated tension head of the reference class (i.e. silty-clay soil), $\psi_{f}^{R}=295[\mathrm{~mm}]$, by means of fixed tabulated ratios between the tension head in each soil class and the tension head of the reference class Dingman (1994) Table 6.1. Finally, computations of evapotranspiration rates are reported, symbols included, in Allen et al. (2005), Eq. (3). The pertinent uncalibrated parameters are (see Allen et al., 2005): the soil moisture at the wilting point $\left(\theta_{W}=0.13\right)$, the maximum depth of water that can be evaporated from the topsoil layer without any restriction $(R E W=8.45 \pm 0.45[\mathrm{~mm}])$, the crop coefficient $k_{c b}$ (which is a function of crop and season), the length of the crop growing phases $l$ (function of crop and season), the crop height during the different growing phases $h$ (function of crop and season).

\begin{tabular}{ll}
\hline Calibrated parameter & Notes \\
\hline$K_{s}^{R}=8 \cdot 10^{-5}[\mathrm{~mm} / \mathrm{s}]$ & $\begin{array}{l}\text { saturated hydraulic conductivity for the reference soil class } R \\
(R=\text { silty-clay agricultural soil) }\end{array}$ \\
$\phi=0.4$ (spring-summer) & overall porosity \\
$\phi=0.5$ (autumn-winter) & surficial soil thickness \\
$Z=0.3[\mathrm{~m}]$ & fraction of infiltrated water contributing to \\
$\eta=0.5($ spring-summer $)$ & the stream response \\
$\eta=0.3($ autumn-winter) & fraction of evaporated water extracted from \\
$\sigma=0.5($ spring-summer $)$ & the surficial soil layer \\
$\sigma=0.9($ autumn-winter) & overland velocity in urbanized areas \\
$v_{u}=2.5 \cdot 10^{-2}[\mathrm{~m} / \mathrm{s}]$ & overland velocity in agricultural areas \\
$v_{a}=4[\mathrm{~mm} / \mathrm{s}](\mathrm{spring}-\mathrm{summer})$ & \\
$v_{a}=3[\mathrm{~mm} / \mathrm{s}]($ autumn-winter $)$ & sub-surficial hillslope's mean residence time \\
$\left.\mu=17\left[\mathrm{hours} /(\mathrm{km})^{2}\right)^{0.38}\right]$ & $\left\langle T_{i}\right\rangle=\mu A_{i}^{0.38} i=1, \ldots, 23$ \\
$a_{i}=(3 / 2) \bar{u}_{i}$ & wave celerity, $L_{i}$ is the $($ measured $)$ reach length \\
$\bar{u}_{i}=1.0[\mathrm{~m} / \mathrm{s}]$ & uniform-flow bankfull velocity \\
$D_{1}=\cdots=D_{23}=1000\left[\mathrm{~m}^{2} / \mathrm{s}\right]$ & hydrodynamic dispersion coefficient \\
& $f_{c_{i}}(t)=\frac{L_{i}}{\sqrt{4 \pi D_{i}} t^{3 / 2}} e^{-\left(L_{i}-a_{i} t\right)^{2} /\left(4 D_{i} t\right)}$ \\
& where $\mathrm{L}_{i}$ is the channel length \\
\hline
\end{tabular}

balance with account of changes in soil use, vegetation and climate in a spatially explicit context. A synthesis of the relevant equations and parameters is reported in Table 2 and in the caption. Note (Table 2) that we allow seasonal variability of the parameters characterizing the soil properties and runoff production processes. In mainly agricultural basins, in fact, the soil conditions are dependent on the type and stage of crop (e.g. autumn and winter plowed areas) and produce an increase of the soil porosity in the upper horizons an obvious increase in retention times. Note also that the seasonal fluctuations of the ground water table affect the fraction of infiltrated water that contribute to the rapid stream response.

Finally, plants are capable of extracting water from depths usually larger than the actual thickness of the hydrologically active soil layer (which has been estimated to be equal to $30 \mathrm{~cm}$ for the basin at hand, see Table 2). Therefore, only a fraction $\sigma$ (e.g. Williams and Albertson, 2004) of the overall evaporation rates has been considered to affect the water balance within the hydrologically active top layer, while the remaining part has been assumed to be drawn from deeper soil layers. The fraction of evaporated water extracted from the topsoil layer $(\sigma)$ is thus the only calibration parameter for the whole evapotranspiration model and its tuning allows to reproduce the dynamics of soil depletion and the temporal variability of the water content between the storms. During autumn and winter season a decreased fraction of cultivated areas determine an increase of the $\sigma$ coefficient (see Table 2). The long-term processes affecting the water balance within soils are responsible for determining the initial water content at the beginning of each rainfall pulse (see Fig. 7 for an example) where the temporal evolution of the modelled soil moisture and of the evapotranspiration flux controlling 
the runoff production is plotted during a sample period of about two months, which is characterized by a pronounced variability in the rainfall rates forcing the system.

\section{Geomorphologic hydrologic response of the Dese river system}

Travel time distributions $f(t)$ at the outlets of the four basins composing the hydrologic system (Fig. 1) are obtained by a suitable decomposition over all the available paths (see Table 1 for the complete specification of the transitions adopted), as described in Part 1 (Eq. 22). Path probabilities are computed in time through the relative fraction of rainfall rates applied over the contributing area (Part 1, Eq. 23). Rainfall fields are estimated by kriging point rainfall measurements (e.g. Fig. 4). The spanning set of subbasins (Fig. 1), each considerably smaller in size than the macroscales of intense rainfall patterns, defines the source areas $\gamma$ where spatially constant rainfall intensities $J(\gamma, t)$ are given (Part 1, Eq. 23).

Most frequently used travel time pdf's in arbitrary channel reaches $c_{i}$ are exactly derived from proper momentum balance equations leading to an inverse Gaussian form for $f_{c_{i}}(t)$ (e.g. Rodriguez-Iturbe and Rinaldo, 1997) (Chapter 7) typically dependent of the reach length $L_{i}$, the celerity of propagation $a_{i}$ and a hydrodynamic dispersion coefficient $D_{i}$ (Table 2). The residence time distribution which characterizes the hillslopes response has been assumed as an exponential distribution, with a mean residence time $\left\langle T_{i}\right\rangle$ dependent on the hillslope area $A_{i}, i=1 \rightarrow 23$ (Table 2, see e.g. Boyd, 1978), a relation devised for other types of terrains that nonetheless proves remarkably accurate in characterizing the contrasting effects of flat but deeply drained unchanneled areas (Rinaldo et al., 2003). Moreover, whether or not one needs to modify travel times depending on the intensity of the hydrologic events (e.g. geomorphoclimatically) or on the modes of hydrologic transport (say when dominated by storage rather than kinematic effects), the basic formal machinery remains unaffected as noted in Part 1 and the above specifications suffice.

The travel time distribution within each path available for hydrologic runoff (see Part 1, Eq. 21) are obtained by the use of nested numerical convolutions in a discrete Fourier transform domain, where (non-cyclic) nested convolutions of pdfs may be expressed as the product of their transforms. Numerically, we employ the Fast Fourier Transform (FFT) algorithm. Flow discharges (Part 1, Eq. 24) are then obtained by routing net rainfall impulses as obtained by the application of the water balance model (Sect. 3) to the estimated rainfall fields.

\section{Mass response functions for nitrates in the Dese river}

In agricultural catchments nitrogen $(\mathrm{N})$ is stored and leached mainly in the form of nitrates $\left(\mathrm{N}_{-} \mathrm{NO}_{3}^{-}\right)$. In the context at hand, nitrate loads carried by hydrologic runoff mainly derive (directly or indirectly) from fertilizations routinely applied onto soil surfaces by agricultural practices. Throughout this exercise we shall assume that external inputs of matter (i.e. through fertilization) becloud nitrogen cycling contributions. Because $\mathrm{NO}_{3}^{-}$is highly soluble under ordinary conditions, nitrates are chiefly stored in the soil moisture within immobile regions, and may be thus transferred to the circulating water carrier. As a result, nitrates are leached by hydrologic runoff, possibly causing serious damages to the ecosystem (soil acidification, $\mathrm{O}_{2}$ impoverishment, eutrophication).

One thus wonders what is the proper reaction kinetics for the description of such processes at basin scales. Specifically, we wonder whether contact times between mobile and immobile waters drive solute mass transfer, and whether such process is fast or slow with respect to characteristic times of the hydrologic response, that is, mean residence times within source areas. Figure 5 shows typical field evidence from simultaneous measurements of discharges and flux concentrations of nitrates $\left(\mathrm{N}-\mathrm{NO}_{3}\right)$, ammonia $\left(\mathrm{N}-\mathrm{NH}_{4}\right)$ and phosphates $\left(\mathrm{P}-\mathrm{PO}_{4}\right)$, normalized to their initial values, at the gauging station for a sizable flood event (Carrer et al., 1997; Bendoricchio et al., 1995, 1999). From the important facts shown therein (and from the bulk of field data e.g. Zaggia et al., 2004; Collavini et al., 2005; Zuliani et al., 2005) we deduce that:

- significant chromatographic effects appear for nitrogen compounds, but possibly not for phosphates. Nitrates show a large delay with respect to the peak of the hydrologic response, implying that the basin-scale transfer from immobile to mobile phases has a characteristic time larger than the lead time of runoff;

- ammonia and phosphates are sorbed onto soil particles, and are released by desorption processes. This is not the case, however, for nitrates which are chiefly solute in soil moisture and mobilized by physical and chemical processes driven by instantaneous differences of mobile and immobile concentrations.

Therefore nitrates show features that are similar to those of a reactive compound. We thus propose to employ the formal machinery described in Part 1 for reactive solutes (although in a somewhat different context with respect to sorption/desorption processes), and rely on the comparison of computed and measured fluxes to assess its validity. The term $\mathrm{N}(t) / k_{D}$ in Eq. (12) (Part 1) here becomes the concentration in immobile phases, while the partition coefficient $k_{D}$ becomes an average coefficient responsible for the transformation of $\mathrm{N}-\mathrm{NO}_{3}$ mass into nitrate concentration in the immobile phase. 


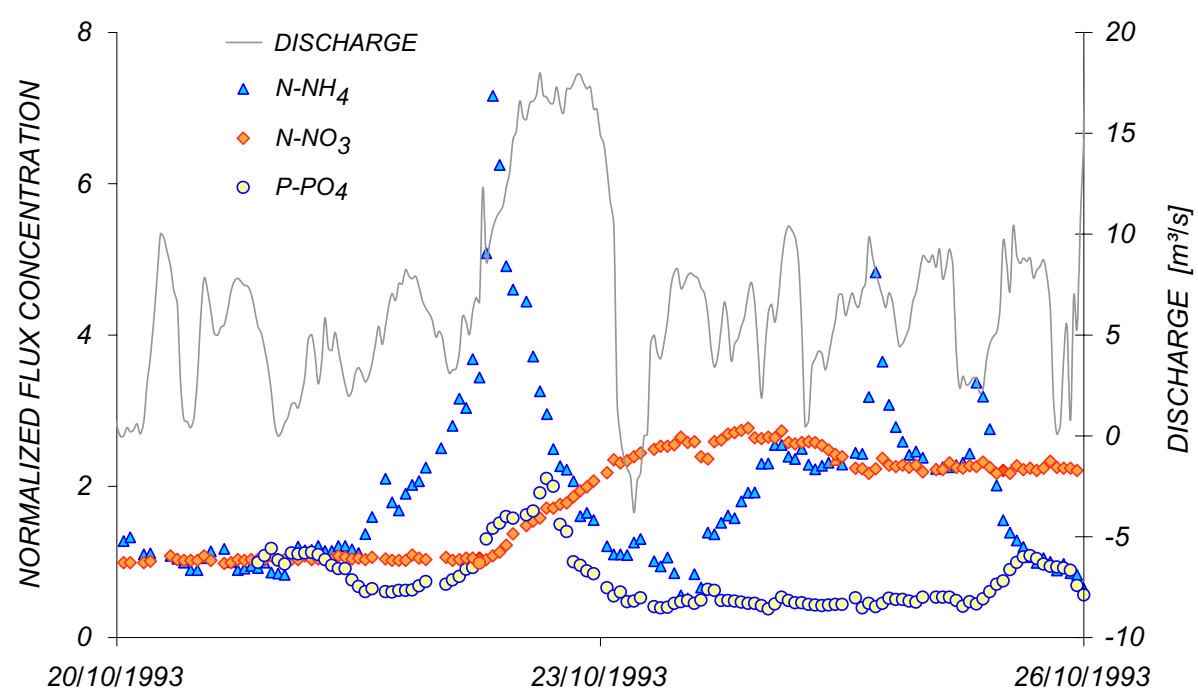

Fig. 5. Field measurements of discharges and flux concentrations of nitrates $\left(\mathrm{N}-\mathrm{NO}_{3}\right)$, ammonia $\left(\mathrm{N}-\mathrm{NH}_{4}\right)$ and phosphates $(\mathrm{P}-\mathrm{PO} 4)$ at the gauging station for the event of October 1993 (after Carrer et al., 1997). For the sake of comparison, measured flux concentrations are normalized to their initial values.
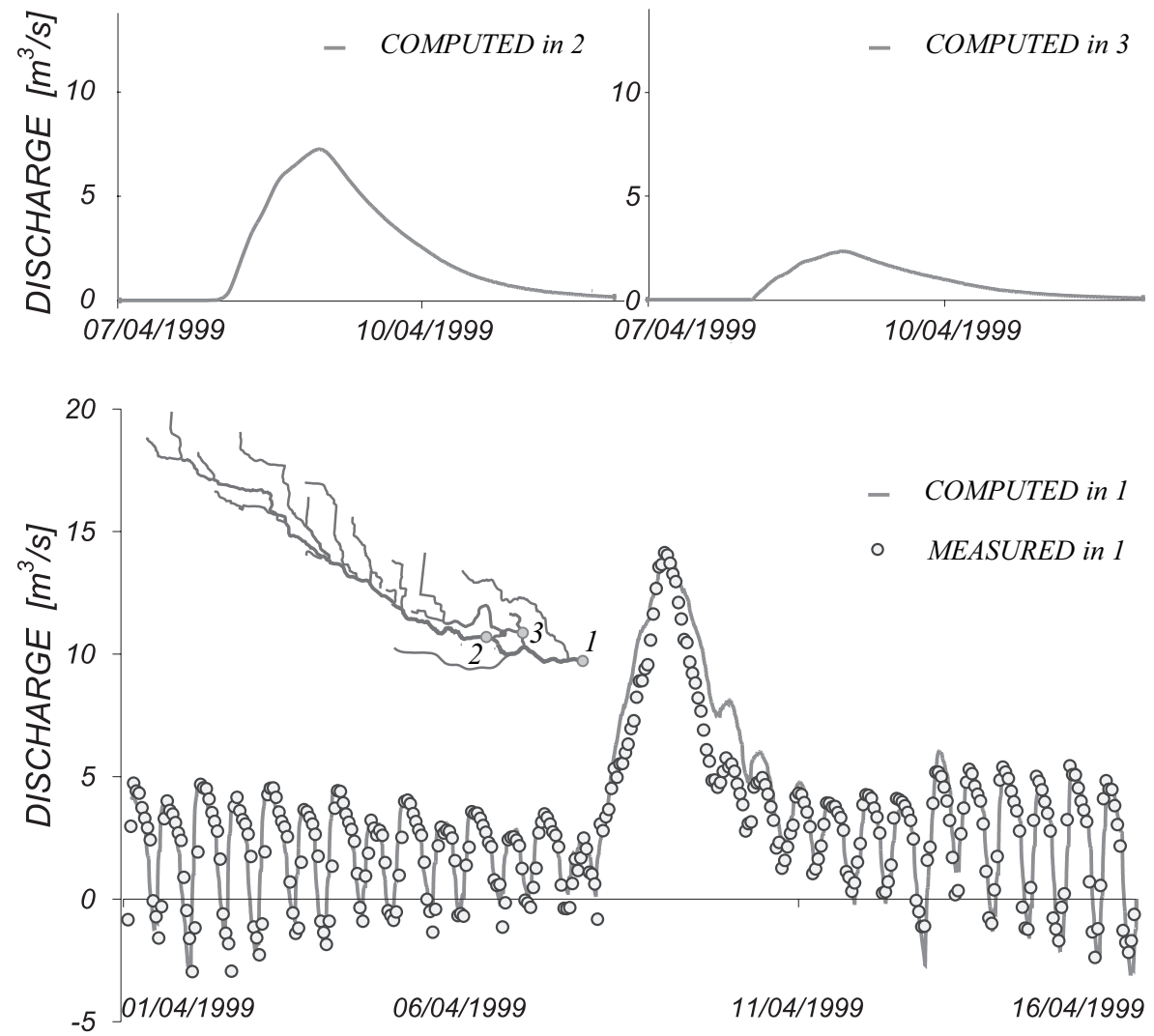

Fig. 6. Calibration of the flow model: measured and computed discharges at the gauging station. The number given in the legend refer to the respective inset.

The basin-scale nitrate flux produced by an arbitrary sequence of rainfall is derived on the basis of the travel time distribution within each state, $f_{x_{i}}$, following the MRF ap- proach described in Part 1 (see Sect. 2, Eqs. 12 and 18). In order to model the solute transport within the source states where solute generation occurs $A_{i}, i=1, \ldots, 23$, three 
different models (A-C) have been employed. A 2-layer approach (A) considers any hillslope as composed by a topsoil layer (where both infiltration and overland flow occur) and a subsurface layer (where the groundwater transport takes place). Two independent mass balances within the layers of each hillslope must be employed to determine the temporal evolution of the nitrates mass in immobile phase. This requires to estimate the mass flux from the topsoil to the deeper layer as well as the mass exchange rate between the mobile and the immobile phases of each layer. The latter has been computed assuming linear and rate-limited reactions, thus allowing the use of Eq. (12) of Part 1. Note that two independent sets of reaction parameters (the initial nitrate concentration in immobile phase $\mathrm{N}(0) / k_{D}$ (Part 1, Eq. 12), and the mass transfer rate $k$ ) should be employed in order to account for the different dynamical and chemical conditions characterizing the transport within the surface and the sub-surface layers. The second model (B) considers each source area as a single layer (whose depth is equal to the sum of the thickness of the surface and of the sub-surface layers) wherein both the overland and the groundwater flows are simultaneously exchanging mass to/from immobile phases. In the latter case, one needs to carry out a single mass balance in time, so as to determine the instantaneous fraction of matter stored in immobile phases. It should be noted that the instantaneous nitrate concentration in the immobile phase of each source, $N_{A_{i}}(t) / k_{D}$, is crucially assumed to solely depend on time $t$ (Botter et al., 2005). Numerically, the temporal evolution of the mobile resident concentration within the $i-t h$ source area, $C_{A_{i}}\left(\tau, t_{0}\right)$, is obtained via an iterative predictorcorrector finite difference scheme where, at each iteration, the unknown value of $\mathrm{N}_{A_{i}}(t)$ (which actually depends on the solution $C$ ) is progressively updated through a global mass balance based on the values of $C$ obtained at the previous iteration. The above approach ensures a good efficiency in terms of computational costs, regardless of the time step employed. Initial conditions for the reaction equation, $N_{A_{i}}(0)$, are assumed proportional to the agricultural fraction within each subbasin (see Fig. 2b - Table 1), thus allowing the estimate of the initial distribution of nitrates concentration in the immobile phase on the basis of a single calibration parameter (the average nitrates mass for unit agricultural surface $\mathrm{N}_{a}$ ). For the sake of simplicity the parameters $k$ and $k_{D}$ in Eq. (12) have been assumed constant and spatially uniform throughout the basin. The third model (C) assumes the local equilibrium assumption (L.E.A.) within mobile and immobile concentrations $\left(C \sim \mathrm{N}(t) / k_{D}\right)$ that correspond to instantaneous reactions $(k \rightarrow \infty)$. This model helps in determining the conditions corresponding to the case when the hydrologic runoff instantaneously dilutes all the nitrate mass stored in the control volume.

We also assume that every source state is followed by a sequence of non-reactive states $x_{2}, x_{3}, \ldots, x_{k}$. This assumption derives from early applications of the more involved procedure (Part 1, Eq. 28) where the solutes transported are actually retarded owing to chemical processes occurring with other immobile phases, e.g. bed sediment or dead zones that define chemical, biological or physical reactions). Owing to the relatively small residence times of the hydrologic carrier within the channeled states, however, the effects of possible reactive components acting within the channels result negligible, thus allowing the simplified approach described by Eq. (27) of Part 1.

Path probabilities, state transitions which define the geomorphic structure of the basin and the travel time distributions $f_{A_{k}}(t), f_{c_{k}}(t)$ within unchanneled and channeled states are the same used for flow prediction without any tuning. This is probably the single most important operational advantage of the proposed procedure as the bulk of solute lifetime distributions (Eq. 26 of Part 1.) is provided by independently assessed travel time distributions.

\section{Linking runoff-generating and transportation zones}

We have already noticed that the subdivision between the solute and runoff generating areas and the transportation zone within the hydraulic network is clearly determined by the nature of the site. Since both the discharges and the nitrate concentrations have been measured at the outlet of the Dese basin (section A, Fig. 1c), where the effect of the tidal fluctuations is not negligible (it routinely inverts even the direction of ebb/flood flows), the description of the system response required the coupling of two distinct transport models: a geomorphological-based catchment model (Sects. 4 and 5) in order to evaluate the runoff production and the nitrogen loss from the agricultural soils of the four basins, and a subsequent one-dimensional flow and transport numerical model accounting for the convection and dispersion phenomena occurring within the reaches actually affected by the tidal fluctuations.

Numerical solution of the flow and transport equations suitably discretizes the main reach between the hydrological outlet of the four basins (section D, Fig. 1c, the hydrologic outlet of the Dese basin; node $E$ in Fig. 1c, for the lower tributary Bazzera; section C, Fig. 1c, for a complex partition of the hydrologic contribution from the Dese river (Rinaldo et al., 2003) and the hydrologic contribution for the tributary Peseggia; and section B, Fig. 1c, for the contribution of Rio Pianton - see also details in Table 1) and the node of Dese (node $A$ in Fig. 1c), which is the outlet of the whole system. Flow boundary conditions are given as forcing water elevations in section A (Fig. 1c) and as forcing discharges at the upstream node of the tidal network (Fig. 1c). The geometry of the tidal reach is described elsewhere, as well as details of the numerical code, a standard second-order time marching scheme with a suitable leapfrog spatial resolution (Rinaldo et al., 2003). The result is a discretized set of water depths and velocities computed in discrete time at suitable cross sections. 


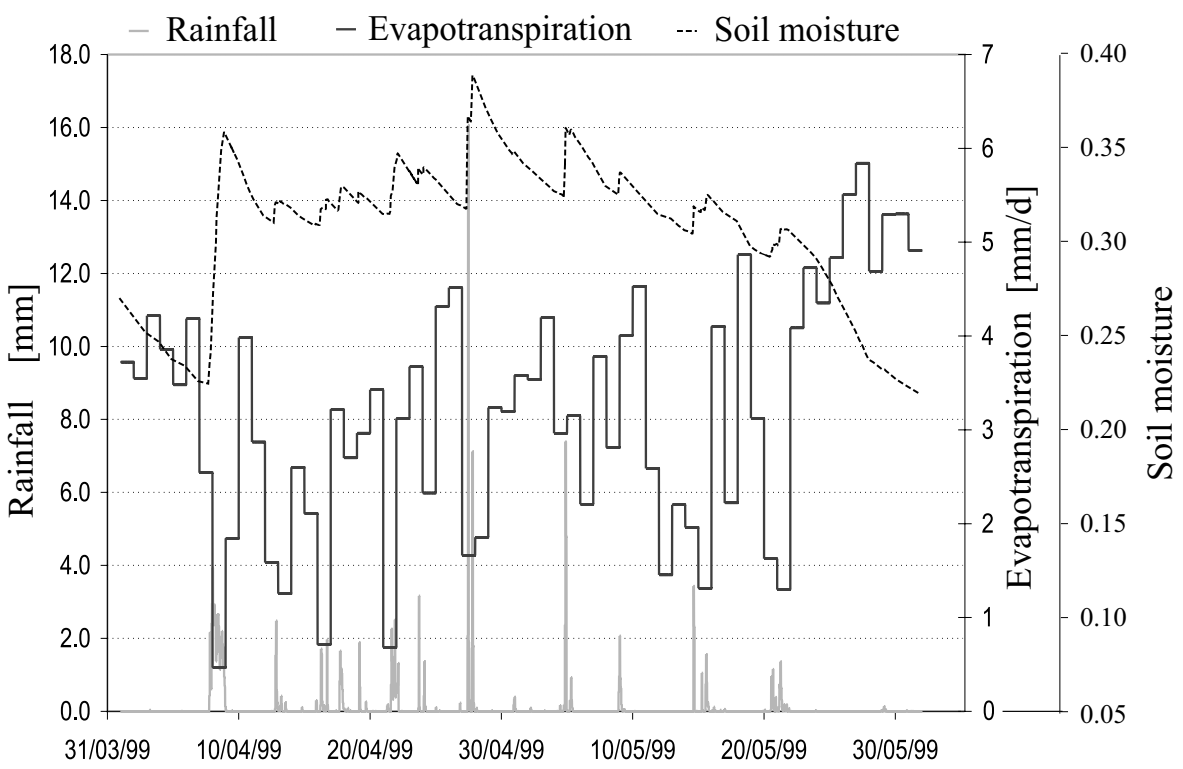

Fig. 7. Sample simulation of continuous runoff production for two months during which the evapotranspiration term and the hydrologic response of the river basin concur in defining the temporal evolution of the soil moisture.
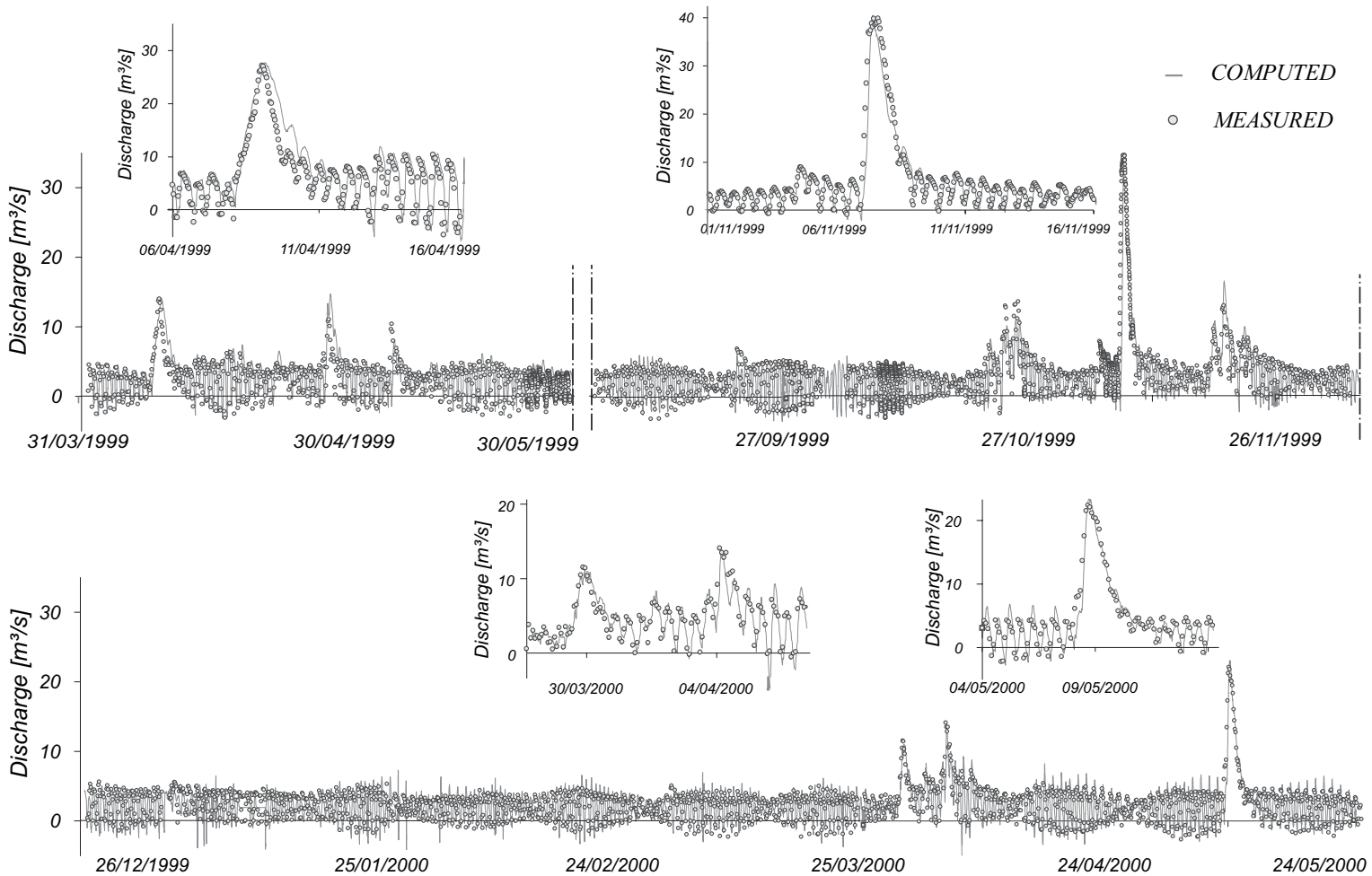

Fig. 8. Validation of the flow model: long term (one year) simulation of the discharge at the outlet of the river basin (comparison between computed and measured time series).

Transport in the tidal reach requires numerical integration of mass balance equations. Details aside (see, for technical details, Rinaldo et al., 2003), we simply recall that the governing equation for the cross-sectional averaged nitrate flux concentration needs be solved along a discretized curvilinear coordinate aligned with the longitudinal axis of the channel. The governing equation is a convection-dispersion model where the main ingredients are: i) the velocity field, directly 
obtained by the unsteady flow model described above; and ii) an appropriate longitudinal, shear-flow hydrodynamic dispersion coefficient, assumed constant as appropriate for mature dispersion processes owing to the much longer longitudinal distances to be covered with respect to vertical and/or transverse mixing lengths (Rinaldo et al., 2003).

Boundary and initial conditions require some attention and a few additional assumptions. Specifically:

- initial concentrations along the tidal reach need to be assumed. A base concentration is assumed almost arbitrarily, because the continuous nature of the model allows actual simulations to forget memory of initial conditions which rapidly become immaterial;

- solute fluxes are specified at the input nodes $B, C, D, E$ as given by Eq. (26) of Part 1. applied to the four subbasins (Dese (D), Peseggia (C), Bazzera (E) and Pianton (B)). Here we assume that the mass flux of hydrologic origin is purely convective, thus neglecting the input diffusive flux at the nodes where the boundaries are imposed. This is strongly supported by hydraulic partitions of runoff generation and transportation zones;

- at the downstream boundary (node A in Fig. 1) where one imposes the water elevations, we need to assume the trapping/pumping exchanges with the downstream water - no simple matter for a general coupled system. Observational evidence (see comparatively Figs. 8 to 10) shows that the strong time variability of tidal water fluxes (that often changes sign) is not paralleled by nitrate concentrations. We thus rule out the possibility that ebb flows are returned clean (say $C(A, t)=0$ if the pertinent flow velocity is negative (i.e. landward)). Our choice of seaward boundary condition is thus $\partial C(x, t) /\left.\partial x\right|_{x=A}=0 \forall t$, whose impact on the numerical results has been deemed acceptable (Sect. 7).

The governing boundary value problem described above has been solved with a suitable numerical scheme, which is able to adjust the time step accordingly with the expected accuracy and uses efficient preconditioned conjugate gradientlike methods (Gambolati et al., 1994). Issues on the algorithms employed can be found elsewhere (Rinaldo et al., 2003).

\section{Results and discussion}

Calibration is pursued by reproducing measured discharges and nitrate concentrations at the outlet of the basin (node A in Fig. 1c). The flow and transport models are calibrated separately and on different flood events: the available data sets (see Sect. 2) consist of frequently sampled measured discharges (at hourly time step) from 1 April 1999 to 31 May 2000 and of two sets of measured nitrate concentrations sampled every half hour, from 20 October to 12 November 1993
(Carrer et al., 1997; Bendoricchio et al., 1999), and from 25 March to 20 May 2000 (Zuliani et al., 2005).

The calibration of the flow model has been performed on the event of April 1999 (see Fig. 6), which is characterized by a peak discharge of $15 \mathrm{~m}^{3} / \mathrm{s}$. An accurate description of the rainfall volume applied to the basin, together with a fine tuning of the parameters controlling runoff production (e.g. hydraulic conductivity, initial soil moisture, soil water content at the field capacity, soil thickness and the infiltrated water that contributes to short term stream response), enables a reasonably correct (and solidly reliable in time) evaluation of the volumes producing the flood. Note that the mathematical model allows to establish a close link between the parameters controlling the processes of infiltration and the different soil uses. The measured hydrograph both during the ascending and the descending limbs is described reasonably well, as shown by Fig. 6, where we show computed and measured discharges at the outlet of the whole system (node 1 in Fig. 6, lower graph). Figure 6 (upper plots) also shows the computed discharges at the outlet of two different ungauged sub-basins: the Dese and the Peseggia catchments (nodes 2 and 3 of Fig. 6, respectively).

The predictive capabilities of the hydrological model is tested through a long term simulation of the response of the system to meteorological forcings from April 1999 to May 2000. Sample Pennmann-Monteith model results during the first months of the simulation period are shown in Fig. 7 through the evapotranspiration terms, which affect the water mass balance within the soil between subsequent rainfall events. Non-stationary conditions in the model include seasonal variability of parameters that are described in Table 2. Figure 8 shows the substantial agreement of the modelled and the measured water discharge during the considered period, both during major rainfall events (which are reported in the insets) and within dry periods when tidal fluctuations significantly affect flows and hydrometric levels at the outlet. We thus conclude that the carrier is well understood.

The transport model requires the calibration of three additional parameters (see Eq. 18 of Part 1): the parameters $k$ and $k_{D}$ and the initial nitrate mass per agricultural unit surface, $\mathrm{N}_{a}$. We calibrate both the 2-layer and the single-layer reactive transport models on the basis of the $\mathrm{N}^{-\mathrm{NO}_{3}}$ measurements collected during the event of October 1993. Figure 9 shows the resulting computed and measured flux concentrations at the outlet (bottom inset). The flux concentrations computed at node 4 (upper right inset) and at the outlets of the Dese and of the Peseggia basins (nodes 2 and 3, upper left inset) via the 2-layer model are also provided. The resulting calibration parameters for the 2- and the single-layer models are shown in Table 3. As shown by Fig. 9 a good agreement between the computed and measured nitrate concentrations at the outlet is achieved. Figure 9 also shows a comparison between the measured $\mathrm{NO}_{3}$ concentrations and the results of the L.E.A. model (C). The delay of the measured breakthrough curve with respect to the temporal evolution 


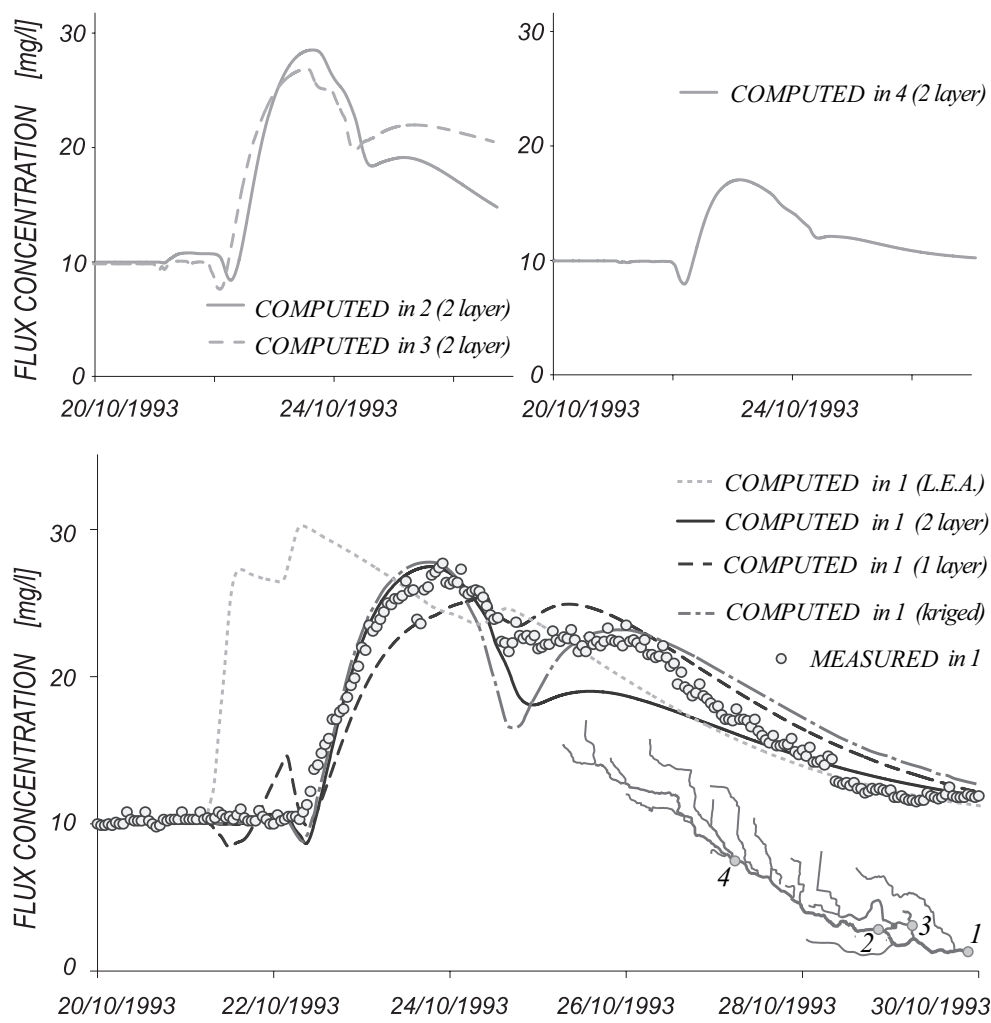

Fig. 9. Calibration of the transport model (event of October 1993): comparison between the computed and measured (Carrer et al., 1997) nitrate concentration at the gauging station. We employ four different models, namely: i) a single-layer local equilibrium model (L.E.A.) with uniform rainfall (dotted line); ii) a 2-layer MRF model with uniform rainfall (solid line); iii) a single-layer MRF model with uniform rainfall (dashed line); iv) a 2-layer MRF model with kriged rainfall (dash-dotted line). The number given in the legend refer to the respective inset.

of the nitrate concentrations from model (C) suggests that slow mass releases from relatively immobile regions of the hillslopes indeed determine a reactive-like behaviour (see Fig. 5). The results shown in Fig. 9 also suggest that the 1-layer model does well in reproducing the main characters of the solute response, because the agreement between the computed and measured $\mathrm{N}-\mathrm{NO}_{3}$ concentration is acceptable. The 2-layer approach provides an improved accuracy during the first days of the event at the cost of an increased number of parameters. Figure 9 also shows the effects of the spatial variability of the rainfall pulses on the computed nitrogen flux concentration at the outlet. The heavier tail of the hydrograph during the last four days of the event leads to a generalized increase of nitrate concentrations. This suggests that the estimate of the total runoff volume plays a major role in shaping the flux concentrations during intense rainfall event, rather than the details of its spatial distribution.

The validation of the nitrogen transport model has been achieved by running the model during two different periods: i) a 20-day span which closely follows the calibration event (from 20 October to 15 November), and ii) a 2-month period during the spring of 2000. The initial nitrate mass for the event of November 1993 has been derived as the residual mass stored in the control volume at the end of the calibration event, while for the second run (spring 2000) we tuned $\mathrm{N}_{a}$ only at the beginning of the whole simulation period (25 March) without any further tuning. From the comparison between the measured and the computed $\mathrm{N}-\mathrm{NO}_{3}$ concentration during the validation period (Fig. 10), one may notice the satisfactory performance of the model, in particular as far as the maximum flux concentrations and the $\mathrm{N}-\mathrm{NO}_{3}$ loads transferred to the Venice lagoon are concerned. Nethertheless, in some cases the model also exhibits a certain inaccuracy in reproducing the timing of the solute release (event of November 1993, Fig. 10a) or details of breakthrough curve (event of April 2000, Fig. 10b). This may be possibly due to a variety of sources: effects of the the flushing of preexisting water characterized by low flux concentrations possibly totally denitrified; or to nitrogen cycling byproducts that we currently consider negiglible. Note finally (Fig. 10) the complexity of the carrier hydrologic flowrates and the contrast with the regularity of simoultaneous nitrate concentrations, both of which are described well by our tools in a predictive mode.

Up to now we have omitted the effects of the long-term variability in the nitrate concentration within the soils, which 
Table 3. Calibration parameters for the 2-layer and for the single-layer transport model. A legend discusses the technicalities involved. The reference equations cited here are reported in the first Paper of this issue.

\begin{tabular}{|c|c|}
\hline Calibrated parameter & Notes \\
\hline \multicolumn{2}{|l|}{1 layer approach } \\
\hline$k=5 \cdot 10^{-6}\left[\mathrm{~s}^{-1}\right]$ & reaction rate (Eq. 18 Part 1$)$ \\
\hline$k_{D}=0.1[\mathrm{ml} / \mathrm{g}]$ & partition coefficient (Eq. 18 Part 1) \\
\hline$N_{a}=108[\mathrm{~kg} / \mathrm{ha}]($ October 1993$)$ & nitrates mass for unit agricultural surface \\
\hline \multicolumn{2}{|l|}{$N_{a}=130[\mathrm{~kg} / \mathrm{ha}]($ April 2000) } \\
\hline$Z=0.6[\mathrm{~m}]$ & overall soil thickness \\
\hline \multicolumn{2}{|l|}{2 layer approach } \\
\hline$k=1 \cdot 10^{-6}\left[\mathrm{~s}^{-1}\right]$ & surficial layer reaction rate \\
\hline$k=5 \cdot 10^{-4}\left[\mathrm{~s}^{-1}\right]$ & sub-surficial layer reaction rate \\
\hline$k_{D}=0.1[\mathrm{ml} / \mathrm{g}]$ & partition coefficient (Eq. 18 Part 1) \\
\hline$N_{a}=150[\mathrm{~kg} / \mathrm{ha}]($ October 1993$)$ & nitrates mass for unit agricultural surface (surf. layer) \\
\hline$N_{a}=20[\mathrm{~kg} / \mathrm{ha}]($ October 1993$)$ & nitrates mass for unit agricultural surface (sub. layer) \\
\hline$Z=0.3[\mathrm{~m}]$ & surficial layer thickness \\
\hline$Z=0.3[\mathrm{~m}]$ & sub-surficial layer thickness \\
\hline
\end{tabular}

is related to slow physical and chemical processes, like mineralization, denitrification due to anaerobic bacteria and plant uptake, a step possibly leading to grossly misled predictions in other contexts. However, relatively simple empirical models may be adopted in predicting long term variations of the nitrate mass between two subsequent rainfall events for different temperatures and soil conditions. In a sample Montecarlo simulation reported in Fig. 11, we show a six-month sample period during which both the intensities and the temporal distribution of the rainfall has been reproduced through a cluster-based stochastic rainfall model of the Bartlett-Lewis type, see e.g. Rodriguez-Iturbe et al. (1987), capable of reproducing the statistical properties of the observed climate. The inter-arrival time between the events and the rainfall intensities are sampled by a Poisson distribution with monthly variable parameters, so as to account for the seasonal variability of the rainfall processes. By coupling the continuous rainfall model with a relatively simple empirical model accounting for the long-term evolution of the nitrate mass within the basin surfaces (for details, see e.g. Rinaldo et al., 1989b) we simulate the nitrate discharge and the time evolution of the nitrate mass stored within the catchment surfaces during the sample period. In Fig. 11 we show the sequence of simulated rainfall intensities generated with the BartlettLewis model (a), the mass discharge at the outlet of the Dese basin (node $D$ of Fig. 1) (b) and the pertinent temporal evolution of immobile nitrate mass (c). The simulation reported in Fig. 11 considers two different scenarios: i) an initial nitrate content $\mathrm{N}_{a}(0)$ of 100 [kg/ha], without any further input during the whole simulation period (solid line) and ii) an initial nitrate load of $100[\mathrm{~kg} / \mathrm{ha}$ ], followed by a single fertilization $(30[\mathrm{~kg} / \mathrm{ha}])$ at the end of June (dotted line). Obviously, the second strategy leads to higher mass discharges, with an in- crease of the nitrate mass stored in the catchment at the end of the simulation. Needless to say, more refined scenarios where both the nitrates loads and the temporal sequence of the fertilizations are treated as random variables may be included within the above framework. This would require a suitable parametrization of many bio-geochemical processes relevant for soil nitrogen cycling. The above framework is designed to estimate, in a proper Montecarlo framework, the return period of the $\mathrm{N}-\mathrm{NO}_{3}$ loads on the basis of the maximum load generated during every simulated year. The model developed in these papers may thus support planning strategies for sustainable land use through reduced environmental impacts of nitrate leaching to fragile ecosystems.

\section{Conclusions}

The following conclusions are worth emphasizing:

- We have applied the organized body of theory presented in Part 1 of this series to a complex watershed where predictions of event-based pollution releases pose challenges and opportunities. The case study is particularly relevant for the complex hydraulic conditions, the wideranging field observations of both flows and flux concentrations, the importance of the estimation of eventbased releases in the management of the planned regulation of the receiving water body (the lagoon of Venice) and the rapidly changing land use scenarios for the entire area;

- the geomorphologic scheme of the hydrologic response works nicely in conjunction with a traditional routing scheme used to describe a tidal reach. Once the 


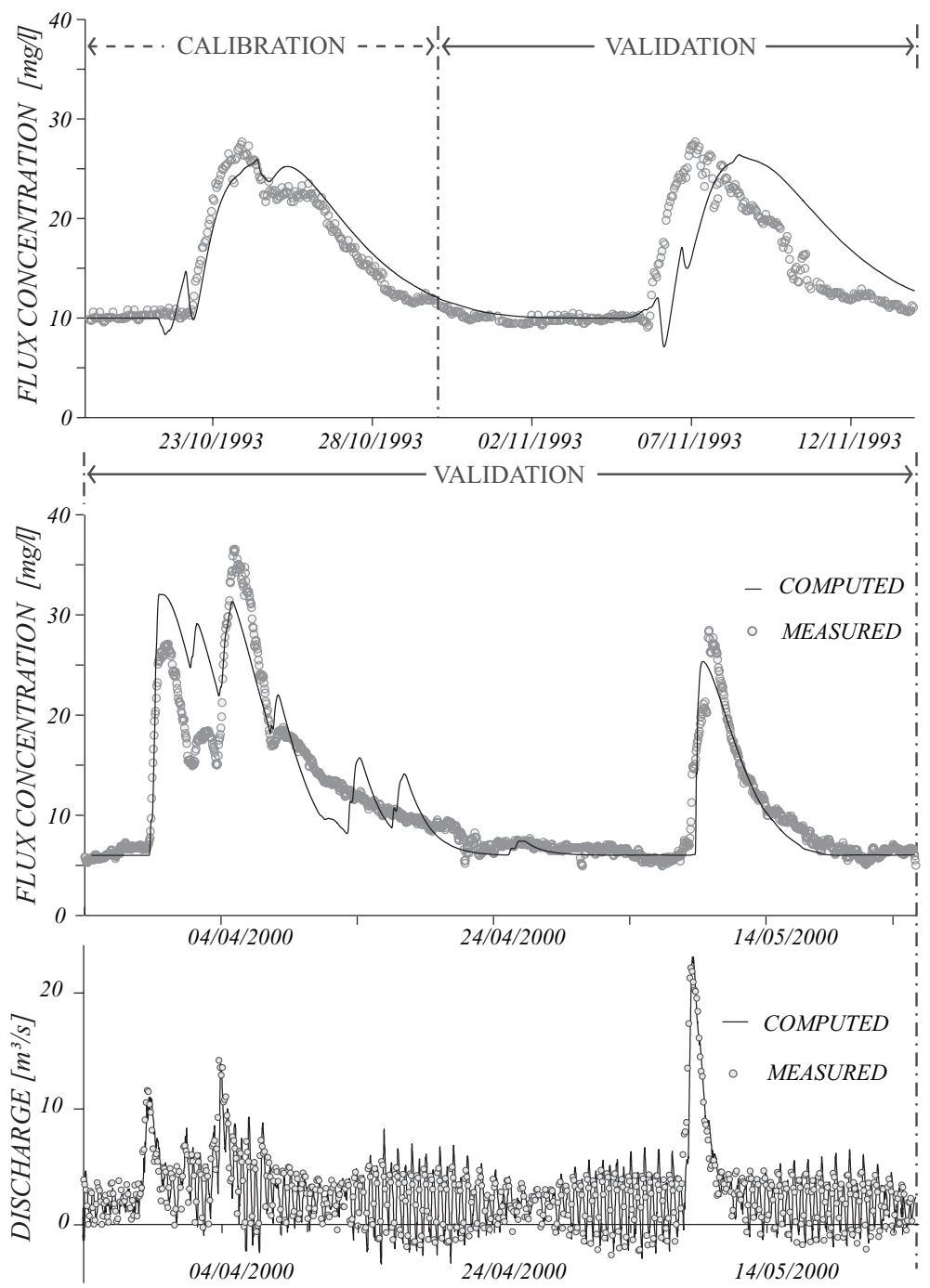

Fig. 10. Validation of the single layer transport model: nitrate concentration computed and measured (Carrer et al., 1997) at the gauging station during different time periods: October-November 1993, and April-May 2000. In the lower graph the temporal evolution of the discharge during April-May 2000 is also reported. Flow measurements are available also during October-November 1993, they are not reported for brevity.

hydrologic scheme has been calibrated, the model runs continuously in time producing almost indistinguishable computed and measured runoffs at the gauging station;

- the mass-response function scheme devised for the description of basin-scale transport in the Dese River assumes that each of the 23 source areas in which we have subdivided the $90 \mathrm{~km}^{2}$ area is generating solute mass through reversible, first-order reactions where the mass stored in immobile phases is proportional to the fraction of agricultural area. Notwithstanding the major simplifications introduced, the model results are satisfactory and suggest a noteworthy potential of the proposed approach for large-scale applications where distributed ap- proaches pose almost unsurmountable problems of parameter calibration for reliable continuous predictions;

- a final section has illustrated the potential of the theoretical tools. In particular, continuous modeling and land-use impact have been investigated within a Montecarlo framework where rainfall and fertilization forcings are treated as random processes (i.e. Poisson interarrivals characterized by exponential intensity).

We thus conclude that mass-response function approaches are suited to describe complex basin-scale transport processes driven by the hydrological response.

Acknowledgements. This research is funded by the EU Project AQUATERRA (GOCE 505428). Financial support provided to 


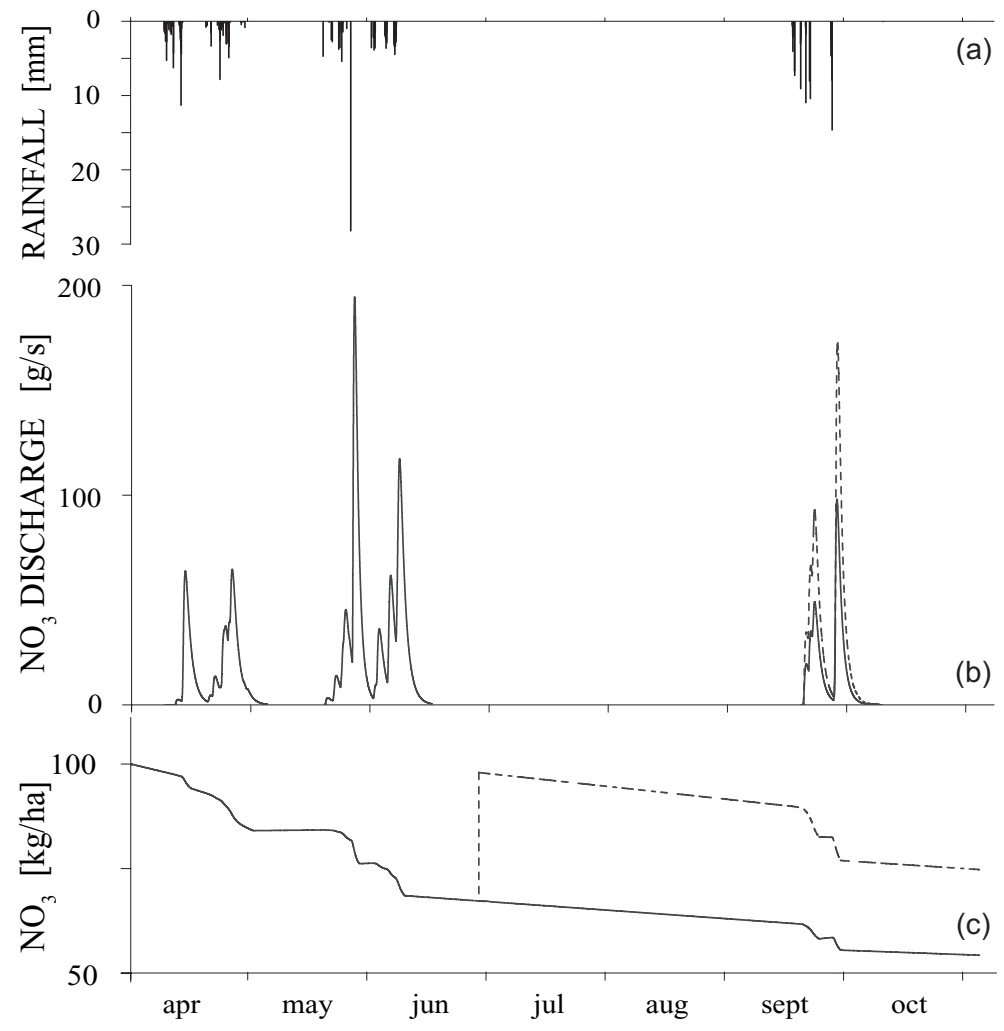

Fig. 11. Sample MonteCarlo simulation for nitrates leaching from the Dese river basin: (a) sequence of synthetic rainfall series generated by the Bartlett-Lewis model. Temporal evolution of the $\mathrm{N}_{-} \mathrm{NO}_{3}$ discharge at the outlet of the catchment (b) and of the $\mathrm{N}-\mathrm{NO}_{3}$ mass stored in immobile phase (c) for different forcing conditions: i) an initial nitrate load $\mathrm{N}_{a}$ of $100 \mathrm{~kg} / \mathrm{ha}$, without any further input during the whole simulation period (solid line) and ii) an initial nitrate load of $100 \mathrm{~kg} / \mathrm{ha}$, followed by a single fertilization (of about $30 \mathrm{~kg} / \mathrm{ha}$ ) at the end of June (dotted line).

G. Botter and M. Marani by CORILA (Consorzio per la Gestione del Centro di Coordinamento delle attività di Ricerca inerenti il Sistema Lagunare) (grant 3.17/2004) is gratefully acknowledged. The writers wish to thank CONSORZIO VENEZIA NUOVA for providing the hydrologic data from a comprehensive database for the area. The writers wish to thank M. Putti, University of Padua, for providing the numerical code solving the convection-dispersion equation used in computing transport in the tidal regime. Field data for nutrient releases have been provided by the late G. Bendoricchio, whom we sorely miss, and by CONSORZIO VENEZIA NUOVA and Magistrato alle Acque di Venezia through their DRAIN project.

Edited by: P. Grathwohl

\section{References}

Allen, R. G., Pereira, L. S., Smith, M., Raes, D., and Write, J. L.: FAO-56 dual crop coefficient method for estimating evaporation from soil and application extensions, J. Irrigation Drainage Eng. ASCE, 131, 2-13, 2005.

Bendoricchio, G., Zingales, F., and Carrer, G. M.: Verifica sperimentale di un modello di simulazione dei carichi di nutrienti all scala di bacino, Ingegneria Ambientale, 24, 5-12, 1995.

Bendoricchio, G., Carrer, G. M., and Calligaro, L.: Consequences of diffuse pollution on the water quality of rivers in the watershed of the lagoon of Venice, Wat. Sci. Tech., 39, 113-120, 1999.

Botter, G. and Rinaldo, A.: Scale effects on geomorphologic and kinematic dispersion, Water Resour. Res., 39(10), 1286, doi:10.1029/2003WR002154, 2003.

Botter, G., Bertuzzo, E., Bellin, A., and Rinaldo, A.: On the Lagrangian formulations of reactive solute transport in the hydrologic response, Water Resour. Res., 41, W04008, doi:10.1029/2004WR003544, 2005.

Boyd, M. J.: A storage routing model relating drainage basin hydrology and geomorphology, Water Resour. Res., 14, 921-928, 1978. 
Brutsaert, W.: Evaporation into the Atmosphere. Theory, History and Applications, Kluwer Academic publishers, New York, 1984.

Carrer, G. M., Calligaro, L., Comis, C., and Zingales, F.: Analisi in continuo dei nutrienti versati nella Laguna di Venezia dal fiume Dese, Atti dell' Accademia Patavina di Scienze, Lettere ed Arti, 60, 21-32, 1997.

Chen, F., Mitchell, K., Schaake, J., Xue, Y. K., Pan, H. L., Koren, V., Duan, Q. Y. E. M., and Betts, A.: Modeling of land surface evaporation by four schemes and comparison with FIFE observations, J. Geophys. Res.-Atmosphere, 101, 7251-7268, 1996.

Collavini, F., Bettiol, C., Zaggia, L., and Zonta, R.: Pollutant loads from the drainage basin to the Venice Lagoon (Italy), Environ. Int., 31(7), 939-947, doi:10.1026/j.envint.2005.05.003, 2005.

Cvetkovic, V. and Dagan, G.: Transport of kinetically sorbing solute by steady random velocity in heterogeneous porous formations, J. Fluid Mech., 265, 189-215, 1994.

Dingman, S. L. M.: Physical Hydrology, MacMillan, New York, 1994.

Gambolati, G., Pini, G., Putti, M., and Paniconi, C.: Finite element modelling of the solute transport of reactive contaminants in variably saturated soils with LEA and non-LEA sorption, Env. Modelling, 2, 173-212, 1994.

Giandon, P., Ragazzi, F., Vinci, I., Fantinato, L., Garlato, A., Mozzi, P., and Bozzo, G. P.: La carta dei suoli del bacino scolante in Laguna di Venezia, Bollettino della Società Italiana della Scienza del Suolo, 50, 273-280, 2001.

Goovaerts, P.: Geostatistics for Natural Resources Evaluation, Oxford University Press, New York, 1997.

Gupta, A. and Cvetkovic, V.: Material transport from different sources in a network of streams through a catchment, Water Resour. Res., 38, 1098, 2002.

Kruse, F. A., Lekoff, A. B., Boardman, J. W., Heiderbrecht, K. B., Shapiro, A. T., Barloon, P. J., and Goetz, A. F. H.: The Spectral Image Processing System (SIPS) - Interactive Visualization and Analysis of Imaging Data, Remote Sensing Environ., 44, 145163, 1993

Marani, M., Lanzoni, S., Silvestri, S., and Rinaldo, A.: Tidal landforms, patterns of halophytic vegetation and the fate of the lagoon of Venice, J. Mar. Systems, 51, 191-210, 2004.
Porporato, A., Laio, F., Ridolfi, L., and Rodriguez-Iturbe, I.: Plants in water-controlled ecosystems: active role in hydrologic processes and response to water stress - III. Vegetation water stress, Adv. Water Resour., 24, 725-744, 2001.

Rinaldo, A. and Marani, A.: Basin scale model of solute transport, Water Resour. Res., 23, 2107-2118, 1987.

Rinaldo, A., Bellin, A., and Marani, A.: On mass response functions, Water Resour. Res., 25, 1603-1617, 1989a.

Rinaldo, A., Marani, A., and Bellin, A.: A study on solute $\mathrm{NO}_{3}-$ $\mathrm{N}$ transport in the hydrologic response by a MRF model, Ecol. Modelling, 48, 159-191, 1989b.

Rinaldo, A., Marani, M., Cudini, E., and Uccelli, A.: Studio Idrologico generale e modello continuo del sistema idraulico DeseZero, Tech. Rep. 7-2003, International Centre for Hydrology "Dino Tonini”, Università di Padova, 148 pp., 2003.

Rinaldo, A., Bertuzzo, E., and Botter, G.: Nonpoint source transport models from empiricism to a coherent theoretical framework, Ecol. Modelling, 184, 19-35, 2005.

Rinaldo, A., Botter, G., Bertuzzo, E., Settin, T., Uccelli, A., and Marani, M.: Transport at basin scales 1. Theoretical Framework, Hydrol. Earth Syst. Sci., 6, 19-29, 2006,

SRef-ID: 1607-7938/hess/2006-10-19.

Rodriguez-Iturbe, I., Cox, D. R., and Isham, W.: Some models for rainfall based on stochastic point processes, Proc. Royal Soc. Lond., A410, 269-288, 1987.

Rodriguez-Iturbe, I. and Rinaldo, A.: Fractal River Basins. Chance and Self-Organization, Cambridge Univ. Press, New York, 1997.

Williams, C. A. and Albertson, J. D.: Soil moisture controls on canopy-scale water and carbon fluxes in an African savanna, Water Resour. Res., 40, W09302, 2004.

Wood, E. F., Sivapalan, M., Beven, K., and Band, L.: Effects of spatial variability and scale with implications to hydrological modelling, J. Hydrol., 102, 29-47, 1988.

Zaggia, L., Zuliani, A., Collavini, F., and Zonta, R.: Flood events and the hydrology of a complex catchment: the drainage basin of the Venice Lagoon, Coast. Environ. V, vol. 68, WIT press, Wessex (UK), 2004.

Zuliani, A., Zaggia, L., Collavini, F., and Zonta, R.: Freshwater discharge from the drainage basin to the Venice Lagoon (Italy), Environ. Int., 31(7), 929-938, doi:10.1016.j.envint.2005.05.004, 2005. 